\title{
Future in mind
}

Promoting, protecting and improving our children and young people's mental health and wellbeing

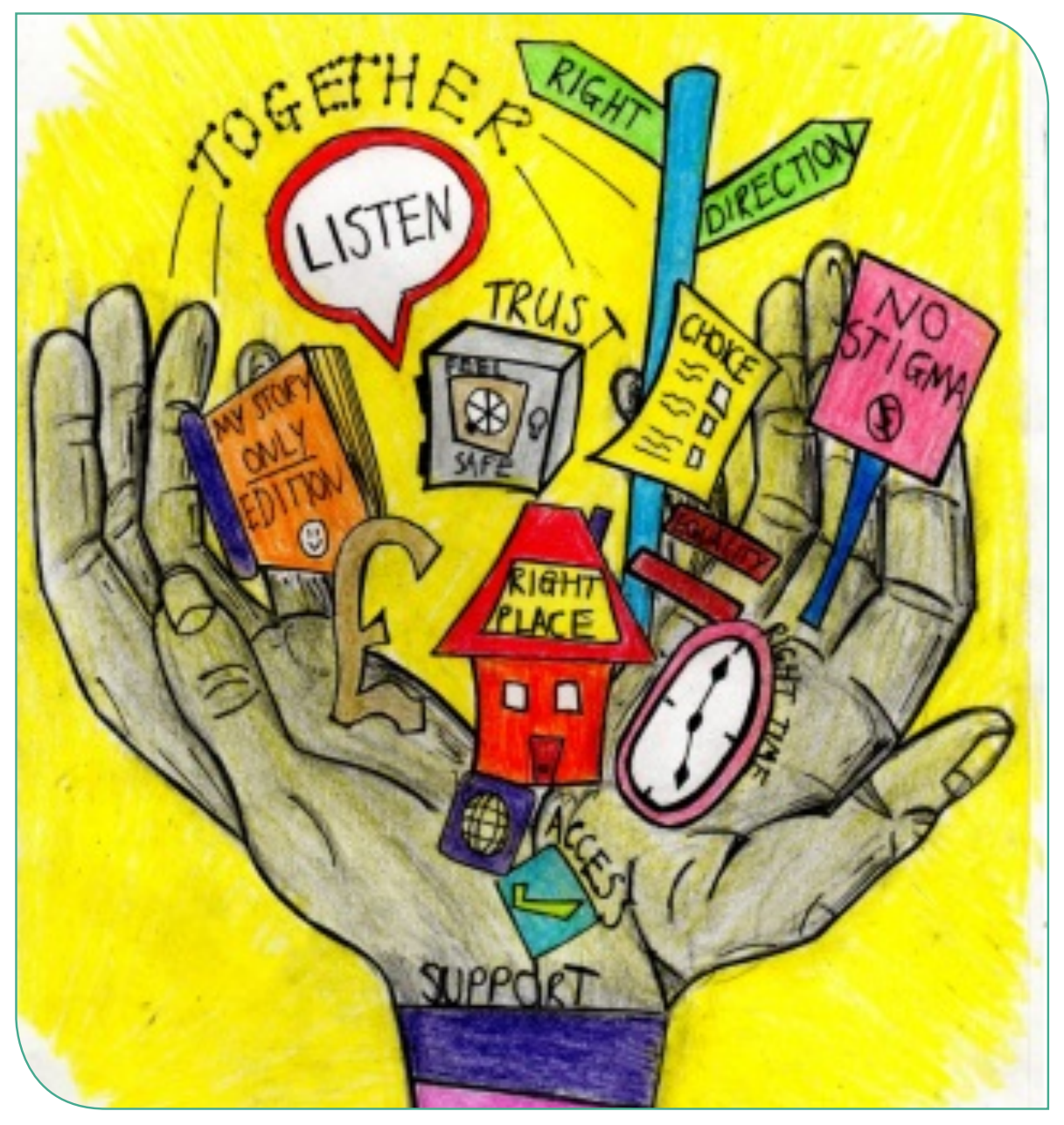


NHS England Publication Gateway Ref. No 02939

The NHS Commissioning Board (NHS CB) was established on 1 October 2012 as an executive non-departmental public body. Since 1 April 2013, the NHS Commissioning Board has used the name NHS England for operational purposes.

(C) Crown copyright

Published to gov.uk, in PDF format only.

www.gov.uk/dh 


\section{Contents}

Foreword from Norman Lamb,

Minister of State for Care and Support

Foreword from Sam Gyimah,

Parliamentary Under Secretary of State,

Department for Education

Foreword from Simon Stevens, CEO of NHS England 7

Your future in mind - an open letter to children and

young people

Our vision for children and young people's mental health 11

\section{The Report}

1. Executive summary and key proposals 13

2. Introduction 21

3. The context and case for change 25

4. Promoting resilience, prevention and early intervention

5. Improving access to effective support - a system without tiers

6. Care for the most vulnerable 51

7. Accountability and transparency 57

8. Developing the workforce 63

9. Making change happen 69

10. Conclusion 73

Glossary and Acronyms 75

Taskforce Membership $\quad 77$

$\begin{array}{ll}\text { Acknowledgements } & 81\end{array}$ 


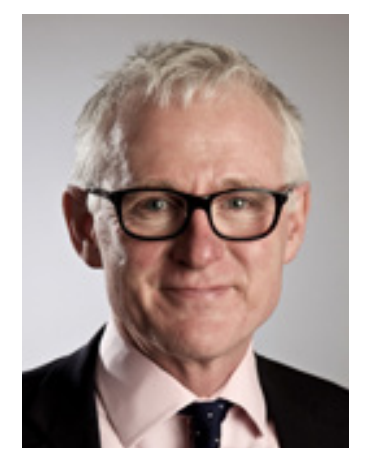

\section{Foreword from Norman Lamb, Minister of State for Care and Support}

Our childhood has a profound effect on our adult lives. Many mental health conditions in adulthood show their first signs in childhood and, if left untreated, can develop into conditions which need regular care.

But, too often, children and young people's emotional wellbeing and mental health is not given the attention it needs. Far too many families have experienced poor children's and adolescent mental health care. This isn't endemic, and we have made great progress in the last few years, but it remains unacceptable that not every child or young person gets the help they need when and where they need it. Some don't get any care at all, and their problems escalate to a crisis point. This isn't due to lack of good will - there are many highly skilled and highly valued staff working with children and young people who want to make a real and lasting difference to their lives but there are barriers in the system itself which prevent change.

I have been changing that system. Since 2011, my Department and NHS England have invested over £60 million in the Children and Young People's Improving Access to Psychological Therapies programme. We have funded the development of MindEd giving more advice to health professionals about how to help young people with mental ill-health. We have put more mental health beds for young people in the system, as well as training new case workers to offer help where it is needed. But this isn't enough - we need to be ambitious if we want children and young people to live happy, healthy lives.

This is why I set up the Children and Young People's Mental Health and Wellbeing Taskforce. I wanted to identify what the problems were, what was stopping us from providing excellent mental health care for young people. The Taskforce brought together professionals from across the education, health and care system to figure this out. They also worked with charities and community organisations and, importantly, they brought in young people and their families, too. We needed a comprehensive view to understand the wide-ranging issues affecting our mental health service.

This is the Government report of the work of the Taskforce and it sets out what we need to do to overcome the status quo. We need a whole child and whole family approach, where we are promoting good mental health from the earliest ages. We need to improve access to interventions and support when and where it is needed, whether that's in schools, GP practices, hospitals or in crisis care. We mustn't think about mental health in a purely clinical fashion. We need to make better use of the voluntary and digital services to fill the gaps in a fragmented system. Crucially, we must make it much easier for a child or young person to seek help and support in non-stigmatised settings. This is where the voluntary sector can be so valuable. We need a simpler system, breaking down the barriers which tiers create, looking at some of the innovative practices which are already happening in this country and abroad.

Anyone who works with or for young people knows that this isn't just about funding. What is needed is a fundamental shift in culture. A whole system approach is needed focusing on prevention of mental ill health, early intervention and recovery. We owe this to young people. It is with their future in mind that we must all commit to, and invest in this challenge. 


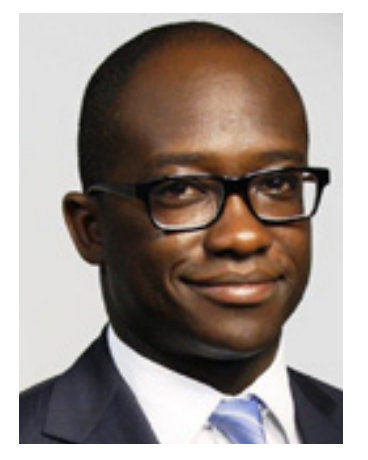

\section{Foreword from Sam Gyimah, Parliamentary Under Secretary of State, Department for Education}

In the Department for Education we want all children and young people to have the opportunity to achieve and develop the skills and character to make a successful transition to adult life. Good mental health is a vital part of that. The challenges young people face are hugely varied - from stress and anxiety about exams to incredibly serious and debilitating long-term conditions. Everyone who works with children and young people has a role in helping them to get the help they need.

That is why I am so pleased to be the first minister in the Department for Education with a specific responsibility for child and adolescent mental health. And why I wanted the department to work closely with the Taskforce to look at how we can make a better offer to children and young people. I believe success in this area comes from Government departments working closely together. We want to make sure young people no longer feel that they have to suffer in silence, that they understand the support that's available for them and that they see mental health services as something that can make a real difference to their lives.

Many schools already support their pupils' mental health. But we can do more to help schools develop knowledge about mental health, identify issues when they arise and offer early support. That is why we have been working alongside the Taskforce to develop work on teaching about mental health with the PSHE Association, and develop a new strategy to encourage more and better use of counselling in schools.
Support can come from other places too. The voluntary sector can be especially effective in reaching out in a way that makes sense to children and young people. That is why DfE has, for the first time, identified mental health as a specific priority within its £25m voluntary sector grant scheme from April we will be supporting a range of exciting projects. Children's services are also looking for innovative ways to make mental health an integral part of support for the most vulnerable, and our Social Care Innovation Programme will continue to fund projects developing this work.

But not every adult who works with children and young people can be a mental health expert. Schools and children's services often raise with me the problems with access to specialist support for children who need it, when what they can provide reaches its limits. That is why I welcome the drive to put the needs of children and young people at the heart of specialist mental health services, to break down the complex tiers of services and to establish clear responsibility for putting in place a coherent offer of services.

This report shows that real success comes from collaboration and sets a challenge to all those working with children and young people. Only by working in partnership, sharing expertise, and making best use of finite resources can we achieve the improvements in mental health outcomes that we all want to see, and make a reality of the vision. 


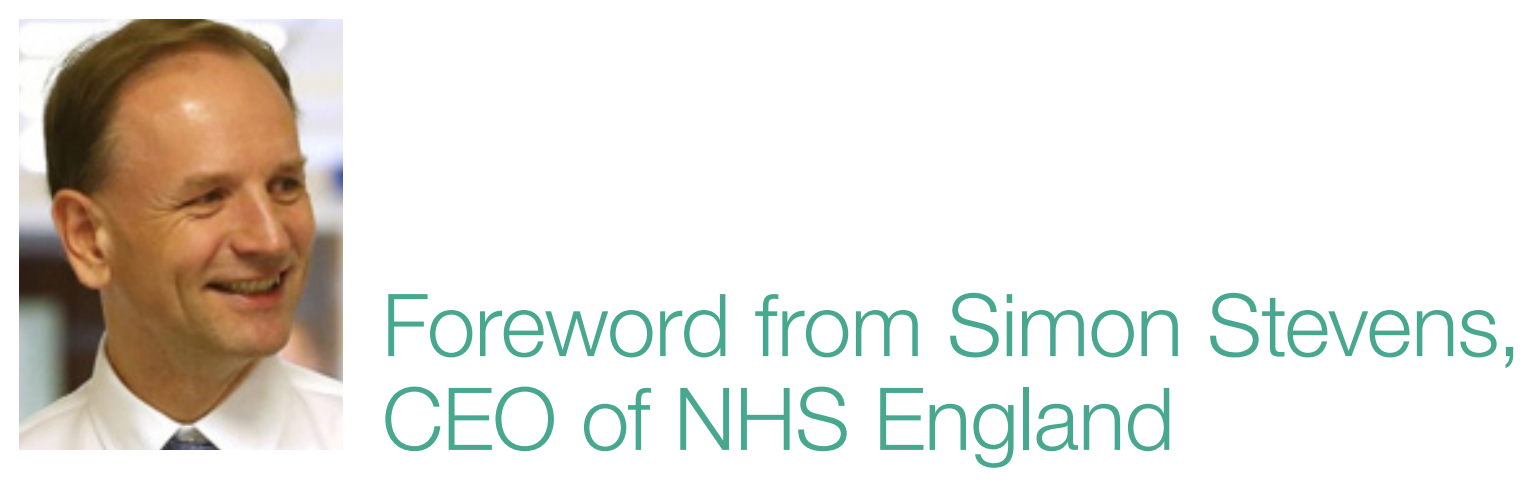

There is now a welcome national recognition of the need to make dramatic improvements in mental health services. Nowhere is that more necessary than in support for children, young people and their families. Need is rising and investment and services haven't kept up. The treatment gap and the funding gap are of course linked.

Fortunately that is now changing. However in taking action there are twin dangers to avoid. One would be to focus too narrowly on targeted clinical care, ignoring the wider influences and causes of rising demand, overmedicalising our children along the way. The opposite risk would be to diffuse effort by aiming so broadly, lacking focus and ducking the hard task of setting clear priorities. This document rightly steers a middle course, charting an agreed direction and mobilising energy and support for the way ahead. I'm pleased to give it NHS England's full support. 


\section{Your future in mind - an open letter to children and young people}

A few months ago, we were asked by the Government to work out what needs to be done to improve children and young people's mental health and wellbeing. Growing up is meant to be one of the very best times in anyone's life but it can also be tough. There are many pressures and some young people, such as looked-after children and those leaving care, are exposed to situations and experiences that can make them particularly vulnerable.

Experiencing mental health concerns is not unusual. At least one in four of the population experience problems at some point in their lives. Over half of mental health problems in adult life (excluding dementia) start by the age of 14 and seventy-five per cent by age 18 . Although mental health issues are relatively common, it is often the case that children and young people don't get the help they need as quickly as they should. As a result, mental health difficulties such as anxiety, low mood, depression, conduct disorders and eating disorders can stop some young people achieving what they want in life and making a full contribution to society.

\section{We were asked to work together and see how your mental health and wellbeing could best be supported to give you the best start in life.}

That means we want to help you acquire the resilience and skills you need when life throws up challenges. We want you to know what to do for yourself if you are troubled by emotions or problems with your mental health. That includes knowing when and how to ask for help and, when you do, to receive high quality care. We want services to be able to respond quickly, to offer support and, where necessary, treatment that we know works, to help you stay or get back on track. We believe that asking people who use services what they think about what happens now is vital. They are the ones who know what needs to change. So our first thought was to ask you - children, young people and those who care for you - how things could work better.

We also knew that lots of good work had been done in the past, so we looked at previous reports and reviewed all the evidence we have. We asked a group of people with a mix of experience and expertise that included young people, parents, people working in schools, in the voluntary sector, and in services as well as people who work for the Government to come together as a 'Taskforce' to help look at all the information we have and think about how we could improve.

What we have come up with is a vision that we hope reflects what you as well as your parents, carers and professionals told us was needed, with ideas about how to make it happen.

We have set out the vision by describing how we think the system should work for young people. The report lays out a map of how we could make those ambitions a reality. In this report, we tell you what we think can change now, but also what we think will take more time. Not all the changes can be made straight away, some are longer term ambitions. But we believe substantial 
progress can be made over the next five years if we act now to make children and young people's mental health a priority.

Do let us know what you think about this report. You can add your comments to our blogs (see links below) and also share your opinions on Twitter using \#youngmentalhealth.

And finally let's remember that there is one change that we can all contribute to. We can all look out for those children and young people who might be struggling right now. We can confront bullying and we can make it OK to admit that you are struggling with your mental health. We can end stigma. And we can support our friends in their treatment and recovery.

Let's make a start.
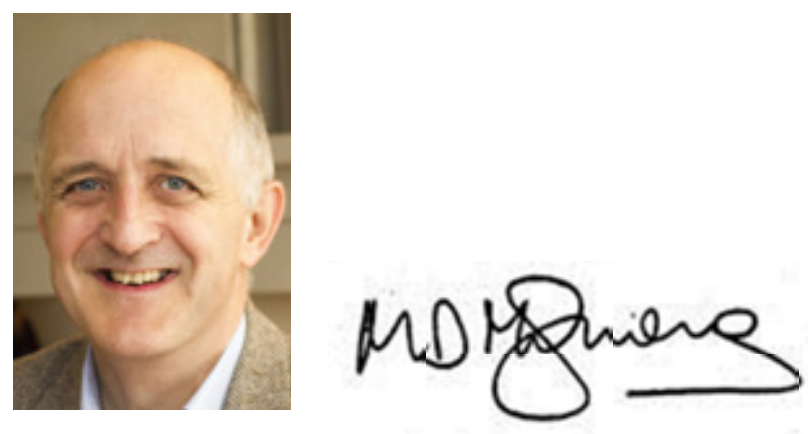

\section{Dr Martin McShane, NHS England}
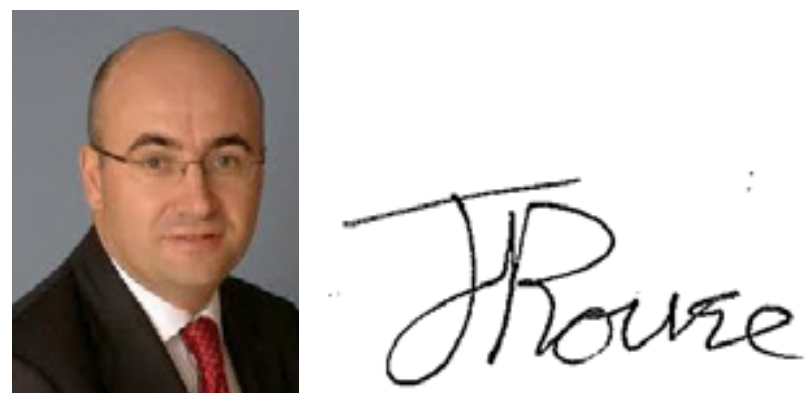

Jon Rouse, Department of Health
Useful links:

Taskforce website: www.gov.uk/government/ groups/children-and-young-peoples-mentalhealth-and-well-being-taskforce Jon Rouse's blog: https://jonrouse.blog.gov.uk/ Dr Martin McShane's blog: www.england. nhs.uk/category/publications/blogs/martinmcshane 


\section{Our vision for children and young people's mental health}

You have goals and ambitions you want to achieve. We want you to grow up to be confident and resilient so you can develop and fulfil these goals and make a contribution to society. To do this we must make sure:

Your parents and carers get the help they need to support you through your childhood and into adult life. Other adults such as GPs, midwives, health visitors, teachers and other people who work in schools, should understand emotional and mental health in children and young people, and know what to do and where to go if they are worried about you or those who care for you.

If you are having difficulty, you shouldn't have to wait until you are really sick to get help, and those around you should be understanding. Asking for help shouldn't be embarrassing or difficult and you should know what to do and where to go.

When you need help, you want to find it easily and to be able to trust it. To make sure this happens, we need to make sure that:

There are websites and apps that you know you can trust and use to help yourself and find out information on how to get more help.

You have a choice about where you can get advice and support from a welcoming place. You might want to go somewhere familiar, such as your school or your doctor. Or you might want to go to a drop-in centre, or access the help you need online. But wherever you go, the advice and support you are offered should be based on the best evidence about what works. All the professionals you meet should treat you as a whole person, considering your physical and mental health needs together.

You are experts in your care and want to be involved in how mental health services are delivered and developed, not just to you and those who support you, but to all the children, young people and families in your area. To do this we must make sure that:

All services give you the opportunity to set your own treatment goals and will monitor with you how things are going. If things aren't going well, the team providing your care will work with you to make changes to achieve your goals. You have the opportunity to shape the services you receive. That means listening to your experience of your care, how this fits with your life and how you would like services to work with you. It means giving you and those who care for you the opportunity to feedback and make suggestions about the way services are provided. Services should tell you what happened as a result.

When you need help, you want it to meet your needs as an individual and be delivered by people who care about what happens to you. This means that:

You should only have to tell your story once, to someone who is dedicated to helping you, and you shouldn't have to repeat it to lots of different people. All the services in your area should work together so you get the support you need at the right time and in the right place. 
If you have a crisis, you should get extra help straightaway, whatever time of day or night it is. You should be in a safe place where a team will work with you to figure out what needs to happen next to help you in the best possible way.

If you need to go to hospital, it should be on a ward with people around your age and near to your home. If you need something very specialised, then you and your family should be told why you need to travel further, and the service should stay in touch to get you home as soon as possible. And while you are in hospital, we should ensure you can keep up with your education as much as you can.

Throughout your care, there are likely to be changes so that you get the right care at the right time. You'll have the opportunity to make informed choices about your treatment and care. You'll keep getting help until you're confident that you're well enough to no longer need it.

If you need help at home, your care team will visit and work with you and your family at home to reduce the need for you to go into hospital. If you do need to go in to hospital, the team should stay in touch and help you to get home quickly.

If you need to move from one service to another, you'll be involved in conversations to prepare you for this and to agree exactly what is happening and when. You'll make the move when you feel ready for it. If you have to move from one area to another, the people responsible for your care will sort this out and involve you, so that you do not have to start from scratch.
You'll keep getting help until you're confident that you're well enough to no longer need it, even if sometimes you can't or don't want to attend appointments. If you don't keep your appointments, someone should get in touch to find out what they can do to help, not just leave you to it.

\section{You want to know that, whatever your circumstances, you get the best possible care, support and treatment when you need it. You'll be able to get help wherever you are in the country, and the help you get where you live won't be worse than if you lived somewhere else. To make this happen we will need to make sure:}

The people responsible for organising and delivering services to you know which services to provide to best help you and other children, young people and families in your community. The people who fund and provide your service should be dedicated to offering the best mental health services possible, and will be honest and open about how they do that as well as about how they are working to improve it. 


\section{Executive summary and key proposals}

1.1 The Children and Young People's Mental Health and Wellbeing Taskforce ${ }^{1}$ was established in September 2014 to consider ways to make it easier for children, young people, parents and carers to access help and support when needed and to improve how children and young people's mental health services are organised, commissioned and provided.

1.2 Key themes emerged which now provide the structure of this report. Within these themes, we have brought together core principles and requirements which we consider to be fundamental to creating a system that properly supports the emotional wellbeing and mental health of children and young people.

\subsection{In summary, the themes are:}

- Promoting resilience, prevention and early intervention

- Improving access to effective support - a system without tiers

- Care for the most vulnerable

- Accountability and transparency

- Developing the workforce

\section{The case for change}

1.4 Mental health problems cause distress to individuals and all those who care for

Children and Young People's Mental Health and Wellbeing Taskforce: Terms of Reference. Available at: www.gov.uk/government/groups/ children-and-young-peoples-mental-health-andwell-being-taskforce them. One in ten children needs support or treatment for mental health problems. These range from short spells of depression or anxiety through to severe and persistent conditions that can isolate, disrupt and frighten those who experience them. Mental health problems in young people can result in lower educational attainment (for example, children with conduct disorder are twice as likely as other children to leave school with no qualifications) and are strongly associated with behaviours that pose a risk to their health, such as smoking, drug and alcohol abuse and risky sexual behaviour.

1.5 The economic case for investment is strong. $75 \%$ of mental health problems in adult life (excluding dementia) start by the age of 18. Failure to support children and young people with mental health needs costs lives and money. Early intervention avoids young people falling into crisis and avoids expensive and longer term interventions in adulthood. There is a compelling moral, social and economic case for change. We set this out in full in Chapter 3.

\subsection{Evidence presented to the Taskforce} also underlined the complexity and severity of the current set of challenges facing child and adolescent mental health services. These include:

i. Significant gaps in data and information and delays in the development of payment and other incentive systems. These are all critical to driving change in a co-ordinated way. 
ii. The treatment gap. The last UK epidemiological study ${ }^{2}$ suggested that, at that time, less than $25 \%-35 \%$ of those with a diagnosable mental health condition accessed support. There is emerging evidence of a rising need in key groups such as the increasing rates of young women with emotional problems and young people presenting with self-harm.

iii. Difficulties in access. Data from the NHS benchmarking network and recent audits reveal increases in referrals and waiting times, with providers reporting increased complexity and severity of presenting problems.

iv. Complexity of current commissioning arrangements. A lack of clear leadership and accountability arrangements for children's mental health across agencies including CCGs and local authorities, with the potential for children and young people to fall though the net has been highlighted in numerous reports. ${ }^{3}$

v. Access to crisis, out of hours and liaison psychiatry services are variable and in some parts of the country, there is no designated health

2 Green H, McGinnity A, Meltzer H, Ford T, Goodman R (2005). Mental health of children and young people in Great Britain, 2004. A survey carried out by the Office for National Statistics on behalf of the Department of Health and the Scottish Executive. Basingstoke: Palgrave Macmillan.

$3 \quad$ National CAMHS Review (2008). Children and young people in mind: the final report of the National CAMHS Review. National CAMHS Review; HM Government (2011). No Health Without Mental Health: A cross-government mental health outcomes strategy for people of all ages. London: Department of Health; Department of Health (2012). Annual Report of the Chief Medical Officer 2012. London: Department of Health; CAMHS Tier 4 Report Steering Group (2014). CAMHS Tier 4 Report. London: NHS England. place of safety recorded by the CQC for under-18s.

\section{vi. Specific issues facing highly} vulnerable groups of children and young people and their families who may find it particularly difficult to access appropriate services.

1.7 These issues are addressed in considering the key themes that form the basis of this report and the proposals it makes.

\section{Making it happen}

1.8 The Taskforce firmly believes that the best mental health care and support must involve children, young people and those who care for them in making choices about what they regard as key priorities, so that evidence-based treatments are provided that meet their goals and address their priorities. These need to be offered in ways they find acceptable, accessible and useful.

\subsection{Providers must monitor, and} commissioners must consider, the extent to which the interventions available fit with the stated preferences of young people and parents/carers so that provision can be shaped increasingly around what matters to them. Services need to be outcomesfocused, simple and easy to access, based on best evidence, and built around the needs of children, young people and their families rather than defined in terms of organisational boundaries.

1.10 Delivering this means making some real changes across the whole system. It means the NHS, public health, local authorities, social care, schools and youth justice sectors working together to:

- Place the emphasis on building resilience, promoting good mental health, prevention and early intervention (Chapter 4) 
- Simplify structures and improve access: by dismantling artificial barriers between services by making sure that those bodies that plan and pay for services work together, and ensuring that children and young people have easy access to the right support from the right service (Chapter 5).

- Deliver a clear joined up approach: linking services so care pathways are easier to navigate for all children and young people, including those who are most vulnerable (Chapter 6), so people do not fall between gaps.

- Harness the power of information: to drive improvements in the delivery of care, and standards of performance, and ensure we have a much better understanding of how to get the best outcomes for children, young people and families/carers and value from our investment (Chapter 7).

- Sustain a culture of continuous evidence-based service improvement delivered by a workforce with the right mix of skills, competencies and experience (Chapter 8).

- Make the right investments: to be clear about how resources are being used in each area, what is being spent, and to equip all those who plan and pay for services for their local population with the evidence they need to make good investment decisions in partnerships with children and young people, their families and professionals. Such an approach will also enable better judgements to be made about the overall adequacy of investment (Chapter 9).
1.11 In some parts of the country, effective partnerships are already meeting many of the expectations set out in this report. However, this is by no means universal, consistent or equitable.

\section{A National ambition}

1.12 This report sets out a clear national ambition in the form of key proposals to transform the design and delivery of a local offer of services for children and young people with mental health needs. Many of these are cost-neutral, requiring a different way of doing business rather than further significant investment.

1.13 There are a number of proposals in this report which require critical decisions, for example, on investment and on local service redesign, which will need explicit support from the next government, in the context of what we know will be a very tight Spending Review. We are realistic in this respect. At both national and local level, decisions will need to be taken on whether to deliver early intervention through an 'invest to save' approach and/or targeted reprioritisation, recognising that it will take time to secure an economic return for the nation. 


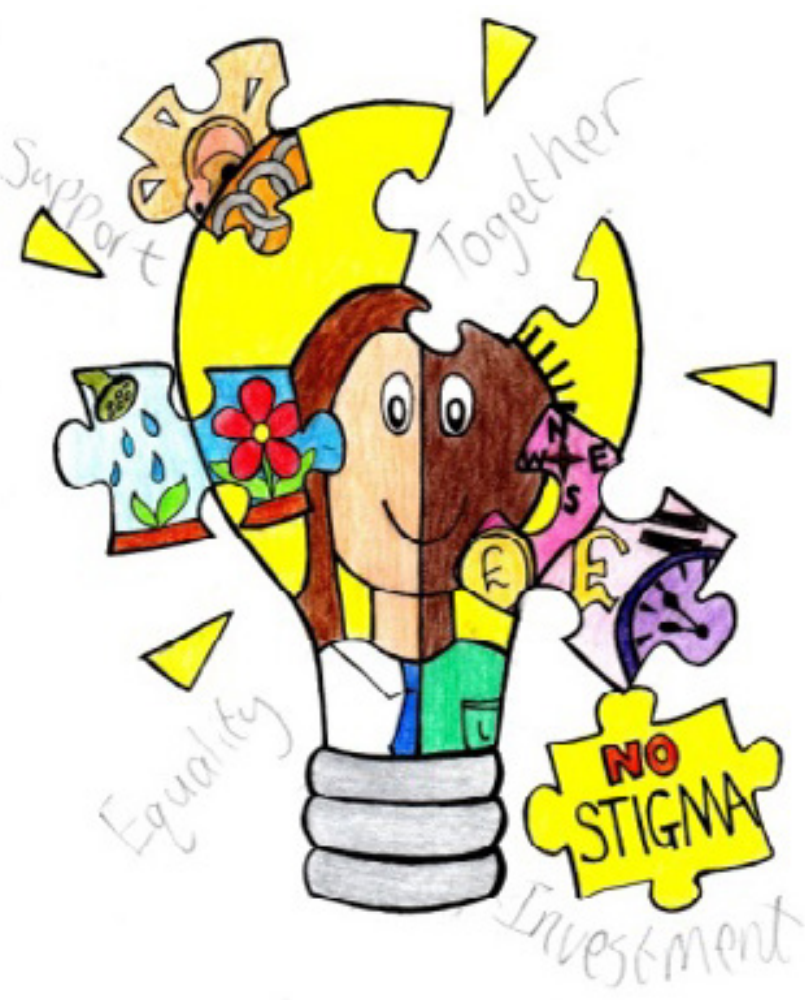

The Government's aspirations are that by 2020 we would wish to see: (The numbers in brackets refer to the proposals in and at the end of each chapter)

1. Improved public awareness and understanding, where people think and feel differently about mental health issues for children and young people where there is less fear and where stigma and discrimination are tackled. This would be delivered by:

- a hard hitting anti-stigma campaign which raises awareness and promotes improved attitudes to children and young people affected by mental health difficulties. This would build on the success of the existing Time to Change campaign; (3)

- with additional funding, we could also empower young people to selfcare through increased availability of new quality assured apps and digital tools. (5)

2. In every part of the country, children and young people having timely access to clinically effective mental health support when they need it. With additional funding, this would be delivered by:

- a five year programme to develop a comprehensive set of access and waiting times standards that bring the same rigour to mental health as is seen in physical health. (17)

3. A step change in how care is delivered moving away from a system defined in terms of the services organisations provide (the 'tiered' model) towards one built around the needs of children, young people and their families. This will ensure children and young people have easy access to the right support from the right service at the right time. This could be delivered by:

- joining up services locally through collaborative commissioning approaches between CCGs, local authorities and other partners, enabling all areas to accelerate service transformation; (48)

- having lead commissioning arrangements in every area for children and young people's mental health and wellbeing services, responsible for developing a single integrated plan. We envisage that in most cases the CCG would establish lead commissioning arrangements working in close collaboration with local authorities. We also recognise the need for flexibility to allow different models to develop to suit local circumstances and would not want to cut across alternative arrangements; (30) 
- transitions from children's services based on the needs of the young person, rather than a particular age. (15)

4. Increased use of evidence-based treatments with services rigorously focused on outcomes. With additional funding, this would be delivered by:

- building on the success of the CYP IAPT transformation programme and rolling it out to the rest of the country. (44)

5. Making mental health support more visible and easily accessible for children and young people. With additional funding, this would be delivered by:

- every area having 'one-stop-shop' services, which provide mental health support and advice to children and young people in the community, in an accessible and welcoming environment. This would build on and harness the vital contribution of the voluntary sector; (16)

- improving communications, referrals and access to support through every area having named points of contact in specialist mental health services and schools. This would include integrating mental health specialists directly into schools and GP practices. (16)

6. Improved care for children and young people in crisis so they are treated in the right place at the right time and as close to home as possible. This would be delivered by:

- ensuring the support and intervention for young people being planned in the Mental Health Crisis Care Concordat are implemented; (12)
- $\quad$ no young person under the age of 18 being detained in a police cell as a place of safety; (19)

- implementing clear evidence-based pathways for community-based care, including intensive home treatment where appropriate, to avoid unnecessary admissions to inpatient care. (13)

7. Improving access for parents to evidence-based programmes of intervention and support to strengthen attachment between parent and child, avoid early trauma, build resilience and improve behaviour. With additional funding, this would be delivered by:

- enhancing existing maternal, perinatal and early years health services and parenting programmes. (4)

8. A better offer for the most vulnerable children and young people, making it easier for them to access the support that they need when, and where they need it. This would include:

- ensuring those who have been sexually abused and/or exploited receive a comprehensive assessment and referral to the services that they need, including specialist mental health services. (24)

9. Improved transparency and accountability across the whole system, to drive further improvements in outcomes. This would be delivered by:

- development of a robust set of metrics covering access, waiting times and outcomes to allow benchmarking of local services at national level; (36)

- clearer information about the levels of investment made by those who 
commission children and young people's mental health services; (38)

- subject to decisions taken by future governments, a commitment to a prevalence survey for children and young people's mental health and wellbeing, which is repeated every five years. (39)

10. Professionals who work with children and young people are trained in child development and mental health, and understand what can be done to provide help and support for those who need it.

\section{Local Transformation Plans}

1.14 Delivering the national ambition will require local leadership and ownership. We therefore propose the development and agreement of Transformation Plans for Children and Young People's Mental Health and Wellbeing which will clearly articulate the local offer. These Plans should cover the whole spectrum of services for children and young people's mental health and wellbeing from health promotion and prevention work, to support and interventions for children and young people who have existing or emerging mental health problems, as well as transitions between services.

1.15 In terms of local leadership, we anticipate that the lead commissioner, in most cases the Clinical Commissioning Group, would draw up the Plans, working closely with Health and Wellbeing Board partners including local authorities. All these partners have an important role to play in ensuring that services are jointly commissioned in a way that promotes effective joint working and establishes clear pathways. Lead commissioners should ensure that schools are given the opportunity to contribute to the development of Transformation Plans.
1.16 To support this, NHS England will make a specific contribution by prioritising the further investment in children and young people's mental health announced in the Autumn Statement 2014 in those areas that can demonstrate robust action planning through the publication of local Transformation Plans.

1.17 What is included in the Plan should reflect the national ambition and principles set out in this report and be decided at a local level in collaboration with children, young people and their families as well as providers and commissioners. Key elements will include commitments to:

\section{Transparency}

- A requirement for local commissioning agencies to give an annual declaration of their current investment and the needs of the local population with regards to the full range of provision for children and young people's mental health and wellbeing.

- A requirement for providers to declare what services they already provide, including staff numbers, skills and roles, waiting times and access to information.

\section{Service transformation}

- A requirement for all partners, commissioners or providers, to sign up to a series of agreed principles covering: the range and choice of treatments and interventions available; collaborative practice with children, young people and families and involving schools; the use of evidence-based interventions; and regular feedback of outcome monitoring to children, young people and families and in supervision.

\section{Monitoring improvement}

- Development of a shared action plan and a commitment to review, monitor 
and track improvements towards the Government's aspirations set out in this Report, including children and young people having timely access to effective support when they need it.

\section{Next steps in 2015/16}

\subsection{At a national level, we will play our part to deliver the ambition by:}

- delivering waiting times standards for Early Intervention in Psychosis by April 2016;

- continuing development of new access and waiting times standards for Eating Disorder;

- commissioning a new national prevalence survey of child and adolescent mental health;

- implementing the Child and Adolescent Mental Health Services Minimum Dataset, which will include the new CYP IAPT dataset;

- continuing to focus on case management for inpatient services for children and young people, building on the response to NHS England's Child and Adolescent Mental Health Services (CAMHS) Tier 4 Report;4

- testing clear access routes between schools and specialist services for mental health by extending the recently established co-commissioning pilots to more areas;

- improving children's access to timely support from the right service through developing a joint training programme to support lead contacts in mental health services and schools. This will be commissioned by NHS England and the
Department for Education and tested in 15 areas in 2015/16. DfE will also support work to develop approaches in children's services to improve mental health support for vulnerable children;

- improving public awareness and understanding of children's mental health issues, through continuing the existing anti-stigma campaign led by Time to Change and approaches piloted in 2014/15 to promote a broader national conversation;

- encouraging schools to continue to develop whole school approaches to promoting mental health and wellbeing through a new counselling strategy for schools, alongside the Department for Education's other work on character and resilience and PSHE.

\subsection{In the medium to longer term, the} Taskforce would like a future government to consider formalising at least some parts of this national ambition to ensure consistency of practice across the country. This would also give a more precise meaning to what is meant by the existing statutory duties in respect of parity of esteem between physical and mental health, as they apply to children and young people. 


\section{Introduction}

2.1 Children and young people's mental health really matters, not only for the individual and their family, but for society as a whole. The evidence tells us that treating different, specific health issues separately will not tackle the overall wellbeing of this generation of children and young people. Their mental and physical health are intertwined, and at the heart of health and wellbeing are their relationships with others. They want an integrated child, youth and family friendly approach that recognises their particular needs, makes them feel supported, emphasises the positives and helps them to cope.

2.2 Over half of all mental ill health starts before the age of fourteen years, and seventy-five per cent has developed by the age of eighteen. ${ }^{5}$ The life chances of those individuals are significantly reduced in terms of their physical health, their educational and work prospects, their chances of committing a crime and even the length of their life. As well as the personal cost to each and every individual affected, their families and carers this results in a very high cost to our economy.

2.3 A great deal of work has been done in recent years to try to address the emotional wellbeing and mental health needs of children and young people. There is a wealth of evidence and good practice to build on. Key

$5 \quad$ Murphy M and Fonagy P (2012). Mental health problems in children and young people. In: Annual Report of the Chief Medical Officer 2012. London: Department of Health. strategies, reports and initiatives include the National Service Framework ${ }^{6}$ in 2004, Every Child Matters in 2003 and the work of the National Advisory Council in 2008.' More recently, the Children and Young People's Health Outcomes Forum ${ }^{8}$ and Chief Medical Officer's Annual Reports in 2012 and 2013 have maintained the focus on improving children's mental health outcomes at national level.

\subsection{The Government has made clear its} commitment that mental health services for people of all ages should have parity of esteem with physical health services ${ }^{9}$ and called on all parts of the health system to put children, young people and their families right at the heart of decision-making and improve every aspect of health services from pregnancy through to adolescence and beyond. ${ }^{10} \mathrm{~A}$ major programme of investment

$6 \quad$ Department of Health (2004). National Service Framework for Children, Young People and Maternity Services. London: Department of Health.

7 National Advisory Council (2011). Making children's mental health everyone's responsibility. London: National Advisory Council.

8 Department of Health (2012). Report of the Children and Young People's Health Outcomes Forum. London: Department of Health.

9 HM Government (2011). No Health Without Mental Health: A cross-government mental health outcomes strategy for people of all ages. London: Department of Health.

10 Department of Health (2013). Improving Children and Young People's Health Outcomes: a system wide response. London: Department of Health. 
and standard-setting has laid the groundwork for significant improvements in the care that children and young people with mental health problems receive.

2.5 Good progress is being made on this agenda with the investment of:

- $£ 60 m$ into the Children and Young People's Improving Access to Psychological Therapies (CYP IAPT) programme over 2011-15/16;

- $\quad £ 7 m$ in an extra 50 CAMHS specialised Tier 4 beds for young patients in the areas with the least provision (as identified by the NHS England CAMHS Tier 4 Report, July 2014);

- $\quad £ 150$ million over the next five years in England to improve services for children and young people with mental health problems, with a particular emphasis on eating disorders; and

- $\quad £ 3$ million in the MindEd e-portal launched in March 2014. The e-portal provides clear guidance on children and young people's mental health, wellbeing and development to any adult working with children, young people and families.

- NHS England is investing £15 million in health provision in the Children and Young People's Secure Estate.

\subsection{Achieving Better Access to Mental} Health Services by $2020^{11}$ outlines the first waiting time standards for mental health and includes a standard which will ensure that by 2016 , at least $50 \%$ of people of all ages referred for early intervention in psychosis services will start treatment within two weeks. This is backed by £40 million investment.

\subsection{Wider cross-government service} transformation initiatives such as the Troubled

11 Department of Health (2014). Achieving Better Access to Mental Health Services by 2020. London: Department of Health.
Families programme aimed at turning around the lives of 120,000 families with a broad range of problems have provided further traction and levers for local areas to make progress. Problems in these families often include mental health issues in either the children or the parents. In response, local authorities are working with families using integrated whole family approaches to address problems collectively for all members of the family.

2.8 The Department for Education (DfE) is leading work to improve the quality of teaching about mental health in Personal, Social, Health, and Economic (PSHE) lessons in schools, and is developing an evidence-based schools counselling strategy to encourage more and better use of counsellors in schools. In addition, DfE has invested £36 million to develop and sustain evidence-based interventions for children in care, on the edge of care or custody and adopted children and their families, such as multisystemic therapy. ${ }^{12}$

\subsection{Since 2011, the Children and Young} People's Improving Access to Psychological Therapies (CYP IAPT) programme for children and young people has supported the transformation of local services. However, there remain significant and unacceptable gaps and variations in consistency and coherence within and across services and how they are commissioned. Services have worked hard to try to keep up with increasing demand, but this has been against a backdrop of fiscal constraint, particularly for local government.

12 Edward Timpson MP on better support for vulnerable adolescents. Addressed to the second European Multisystemic Therapy Conference. London, 12 May 2014. Transcript available at: www.gov.uk/government/speeches/edwardtimpson-on-better-support-for-vulnerableadolescents 
2.10 At a service level, we know the importance of directly involving children, young people and their parents and carers in their own treatment, setting goals that have a meaning for them and using their feedback to guide their treatment and overall service development: it pays dividends in making services effective and efficient. Our knowledge about the evidence base has grown, and we have a much clearer picture of good models of care and how best to integrate services through strong collaborative working across the statutory, independent and voluntary and community sectors.

2.11 We therefore have some good work on which to build. However, this has to be set against a context of many local and specialist services struggling to cope with what benchmark surveys ${ }^{13}$ demonstrate is increasing demand in a very tight financial environment. The Taskforce also found a lack of consistency in local systems' approach to, and prioritisation of child mental health. The next chapter of the report sets out the case for change in some detail, but we would want to make clear from the outset that there is an urgent need for change.

2.12 Last autumn, the publication of the NHS Five Year Forward View ${ }^{14}$ brought statutory organisations together around a vision for the future of health and care in England that emphasises prevention, new models of care and local determination within national frameworks.

\subsection{Nowhere could these principles be} more relevant than in supporting the mental health and wellbeing of children and young people. To this end, the Minister for Care and Support, supported by colleagues in other government departments, set up the

$13 \quad$ NHS Benchmarking Collaborative 2014 - see www.nhsbenchmarking.nhs.uk/index.php

14 NHS England (2014). Five Year Forward View. London: NHS England.
Children and Young People's Mental Health and Wellbeing Taskforce, co-chaired by the Department of Health and NHS England, to gather insights and evidence and inform this report.

2.14 The core group met five times, with a membership of over 60 participants from across health, social care, youth justice and education. Four working groups were formed, involving Taskforce members and others with specialist expertise, to look at the issues in more detail. 1600 children, young people, parents and carers were also involved through engagement activity led by YoungMinds. It is their voice and their experience which have been central to guiding and shaping this report.

2.15 This report has taken feedback from the working groups in the Taskforce, the engagement with children and young people, parents, carers and professionals and collated it with the established evidence base and previous reports. The work of the Taskforce was characterised from the outset by a shared sense of purpose that real change is necessary and, over time, achievable.

2.16 A number of key themes rapidly emerged. There is a need for good, transparent, regular data and information that is collected nationally. Prevention and early intervention are not only desirable but costeffective. Support and treatment, especially in a crisis, need to be coordinated to make sure that different organisations and professionals know where responsibility lies and how to act effectively together. In addition, the needs of the more vulnerable should be recognised and addressed so they are not neglected or marginalised. Finally, interventions need to be evidence-based or contribute to research and evaluation so that the finite resources available are used to best effect. 
2.17 These themes form the basis of this report and guide the principles it sets out and the changes it proposes.

2.18 Some of the most significant decisions will require consideration by an incoming Government with a full term ahead of them. But there is also much that can be started now. The Taskforce has found examples of existing best practice from around the country and there is plentiful scope for further local as well as national innovation.

2.19 There is no time to waste. 


\section{The context and case for change}

3.1 The prevalence of mental health problems in children and adolescents was last surveyed in 2004. This study estimated that: ${ }^{15}$

- $9.6 \%$ or nearly 850,000 children and young people aged between 5-16 years have a mental disorder

- $7.7 \%$ or nearly 340,000 children aged 5-10 years have a mental disorder

- $11.5 \%$ or about 510,000 young people aged between 11-16 years have a mental disorder

- This means in an average class of 30 schoolchildren, 3 will suffer from a diagnosable mental health disorder ${ }^{16}$

3.2 The most common diagnostic categories were conduct disorders, anxiety, depression and hyperkinetic disorders.
15 Green H, McGinnity A, Meltzer H, Ford T, Goodman R (2005). Mental health of children and young people in Great Britain, 2004. A survey carried out by the Office for National Statistics on behalf of the Department of Health and the Scottish Executive. Basingstoke: Palgrave Macmillan.

16 YoungMinds Mental Health Statistics. Available at: www.youngminds.org.uk/training_services/policy/ mental_health_statistics

\section{Common mental health issues affecting children and young people}

Conduct disorders:

- $5.8 \%$ or just over 510,000 children and young people have a conduct disorder.

Anxiety:

- $3.3 \%$ or about 290,000 children and young people have an anxiety disorder.

\section{Depression:}

- $0.9 \%$ or nearly 80,000 children and young people are seriously depressed.

Hyperkinetic disorder (severe ADHD):

- $1.5 \%$ or just over 132,000 children and young people have severe ADHD.

\subsection{Children with mental health problems} are at greater risk of physical health problems; they are also more likely to smoke than children who are mentally healthy. Children and young people with eating disorders and early onset psychosis are particularly at risk, but it is important to note that many psychotropic drugs also have an impact on physical health.

3.4 Children with physical health problems also need their mental wellbeing and health supported. 


\section{The interface between mental and physical health}

- $12 \%$ of young people live with a long-term condition (LTC) (Sawyer et al 2007).

- The presence of a chronic condition increases the risk of mental health problems from two-six times (Central Nervous System disorders such as epilepsy increase risk up to six- fold) (Parry-Langdon, 2008; Taylor, Heyman \& Goodman 2003).

- $12.5 \%$ of children and young people have medically unexplained symptoms, one third of whom have anxiety or depression (Campo 2012). There is a significant overlap between children with LTC and medically unexplained symptoms, many children with long term conditions have symptoms that cannot be fully explained by physical disease.

- Having a mental health problem increases the risk of physical ill health. Depression increases the risk of mortality by $50 \%{ }^{17}$ and doubles the risk of coronary heart disease in adults. ${ }^{18}$

- People with mental health problems such as schizophrenia or bipolar disorder die on average $16-25$ years sooner than the general population. ${ }^{19}$

\section{Economic argument}

3.5 The economic case for addressing child and adolescent mental wellbeing is a strong one.

17 Mykletun A, Bjerkeset O, Overland S, Prince M, Dewey M, and Stewart R (2009). Levels of anxiety and depression as predictors of mortality: the HUNT study. British Journal of Psychiatry 195: 118-125.

18 Hemingway $\mathrm{H}$ and Marmot M (1999). Evidence based cardiology: psychosocial factors in the aetiology and prognosis of coronary heart disease. A systematic review of prospective cohort studies. British Medical Journal 318: 1460-1467; Nicholson A, Kuper H and Hemingway $\mathrm{H}$ (2006). Depression as an aetiologic and prognostic factor in coronary heart disease: a meta-analysis of 6362 events among 146 538 participants in 54 observational studies. European Heart Journal 27: 2763-2774.

19 Parks J, Svendsen D, Singer P, Fonti ME, and Mauer B (2006). Morbidity and Mortality in People with Serious Mental IIIness (Thirteenth in a Series of Technical Reports). Alexandria, Virginia: National Association of State Mental health Program Directors (NASMHPD) Medical Directors Council.

\subsection{Mental health problems not only} cause distress, but can be associated with significant problems in other aspects of life and affect life chances.

\subsection{Despite this burden of distress, it} is estimated that as many as $60-70 \%$ of children and adolescents who experience clinically significant difficulties have not had appropriate interventions at a sufficiently early age. ${ }^{20}$ Evidence shows that, for all these conditions, there are interventions that are not only very effective in improving outcomes, but also good value for money, in some cases outstandingly so, as measured by tangible economic benefits such as savings in subsequent costs to public services. ${ }^{21}$

20 Children's Society (2008) The Good Childhood Inquiry: health research evidence. London: Children's Society

21 Fonagy P, Cottrell D, Phillips J, Bevington D, Glaser D, and Allison E (2014). What works for whom? A critical review of treatments for children and adolescents (2nd ed.). New York, NY: Guilford Press. 


\subsection{The evidence base, both clinical} and economic, for other conditions, such as eating disorders, self-harm or autistic spectrum disorders is not as strong, but the moral and ethical arguments to care, research and build an evidence base are undeniable.

3.9 The B-CAMHS surveys of mental health of children and adolescents show all forms of mental disorder are associated with an increased risk of disruption to education and school absence. ${ }^{22,23}$ Research on the longer-term consequences of mental health problems in childhood adolescence has found associations with poorer educational attainment and poorer employment prospects, including the probability of 'not being in education, employment or training' (NEET). ${ }^{24}$

3.10 There is a strong link between parental (particularly maternal) mental health and children's mental health. Maternal perinatal depression, anxiety and psychosis together carry a long term cost to society of just under $£ 10,000$ for every single birth in the country (see paragraph 4.4).

22 Meltzer H, Gatward R, Goodman R, Ford $T$ (1999). The mental health of children and adolescents in Great Britain. The report of a survey carried out in 1999 by Social Survey Division of the Office for National Statistics on behalf of the Department of Health, the Scottish Health Executive and the National Assembly for Wales. London: The Stationery Office.

23 Green H, McGinnity A, Meltzer H, Ford T, Goodman R (2005). Mental health of children and young people in Great Britain, 2004. A survey carried out by the Office for National Statistics on behalf of the Department of Health and the Scottish Executive. Basingstoke: Palgrave Macmillan.

24 Goodman A, Joyce R, Smith JP (2011). The long shadow cast by childhood physical and mental health problems on adult life. Proc Natl Acad Sci 108(15): 6032-6037.
3.11 Social relationships can be affected both in childhood and adolescence and in adult life. Other increased risks include drug and alcohol use. Conduct disorder and ADHD are also both associated with an increased risk of offending and conduct disorder in girls with an increased risk of teenage pregnancy.

\subsection{Bullying is reported by $34-46 \%$ of} school children in England in recent surveys. A dose-response relationship exists, which means that children who are exposed to frequent, persistent bullying have higher rates of psychiatric disorder. Exposure to bullying is also associated with elevated rates of anxiety, depression and self-harm in adulthood. ${ }^{25}$

3.13 As well as the impact on the individual child and family, mental health problems in children and young people result in an increased cost to the public purse and to wider society. Those with acute conduct disorder incur substantial costs above those with some conduct problems, but not conduct disorder. A study by Friedli and Parsonage ${ }^{26}$ estimated additional lifetime costs of around $£ 150,000$ per case - or around £5.3bn for a single cohort of children in the UK. Costs relating to crime are the largest component, accounting for $71 \%$ of the total, followed by costs resulting from mental illness in adulthood (13\%) and differences in lifetime earnings (7\%). More widely, in 2012/13, it was estimated the total NHS expenditure on dedicated children's mental health services was £0.70bn.

25 Copeland WE, Wolke D, Angold A, Costello EJ (2013). Adult psychiatric outcomes of bullying and being bullied by peers in childhood and adolescence. JAMA Psychiatry 70(4): 419-426.

26 Friedli L, Parsonage M (2007). Mental Health Promotion: Building an Economic Case. Northern Ireland Association for Mental Health. 


\subsection{In straitened financial times, ensuring} best value for the taxpayer investment is vital. The Centre for Mental Health has analysed the return on investment from addressing the four common disorders in childhood. ${ }^{27}$ For instance, it has been estimated that children with early conduct disorder are 10 times more costly to the public sector by the age of 28 than other children. ${ }^{28}$

3.15 The impact of mental health disorders extends beyond the use of public services. Taking this wider societal viewpoint, it has been estimated that the overall lifetime costs associated with a moderate behavioural problem amount to £85,000 per child and with a severe behavioural problem £260,000 per child. ${ }^{29}$

"The strength of the mental health of our future adult population is the responsibility of all departments of society - health, education, policing etc... children and young people with mental health difficulties cost all of these departments more money - it is in everyone's best interest to invest in the children and young people of today."

A family support worker who took part in the Taskforce engagement exercises

27 Khan L, Parsonage M, Stubbs J for CentreForum's Mental Health Commission (2015). Investing in children's mental health: a review of evidence on the costs and benefits of increased service provision. London: Centre for Mental Health.

28 Scott S, Knapp M, Henderson J, Maughan B. (2001). Financial cost of social exclusion: followup study of antisocial children into adulthood. British Medical Journal 323(7306): 191.

29 Parsonage M, Khan L, Saunders A (2014). Building a better future: the lifetime costs of childhood behavioural problems and the benefits of early intervention. London: Centre for Mental Health.
3.16 The National Institute for Health and Care Excellence (NICE) documents a wide range of well-evidenced interventions that can be used to treat children and young people with mental health disorders effectively. ${ }^{30}$ For example, the table below details the impact of group cognitive behavioural therapy for depressed adolescents.

3.17 It is important to note that this does not include wellbeing gains, but does measure the financial benefit to an individual due to improved employment opportunities as a result of managing their condition.

\subsection{The benefits included in a benefit:cost} ratio are in addition to the mental health and wellbeing improvements associated with evidenced interventions. In general, measured benefits include two main elements: (i) reductions in the use of public services because of better mental health, and (ii) increases in earnings associated with the impact of improved mental health on educational attainment. In the case of conduct disorder, there are also benefits to society resulting from reduced offending, including costs to victims and the community.

\subsection{The inescapable fact is that failure to} prevent and treat children and young people's mental health problems comes at a heavy price, not only for the wellbeing of the children concerned and their families, but also for taxpayers and society because of increased future costs.
$30 \quad$ National Institute for Health and Care Excellence. Mental health and wellbeing guidance. Available at: http://www.nice.org.uk/guidance/lifestyle-andwellbeing/mental-health-and-wellbeing 


\begin{tabular}{|l|l|}
\hline Group Cognitive Behavioural Therapy (CBT) for depressed adolescents \\
\hline Aim & $\begin{array}{l}\text { Group CBT for depressed adolescents aims } \\
\text { to improve general functioning and prevent } \\
\text { the risk of a major depressive episode from } \\
\text { occurring. It is a series of group sessions } \\
\text { lead by a therapist, involving exploring ideas } \\
\text { related to the condition and how to handle } \\
\text { it. There is a suggested duration of three } \\
\text { months of weekly meetings. }\end{array}$ \\
\hline Unit Cost & $£ 229$ \\
Total lifetime benefit & $£ 7,252$ \\
Lifetime benefit to taxpayers & $£ 3,520$ \\
Lifetime benefit to participants & $£ 3,455$ \\
Lifetime benefit to others & $£ 277$ \\
Lifetime benefit-cost ratio (benefits/costs) & 31.67 \\
\hline
\end{tabular}

\section{Levels of Investment}

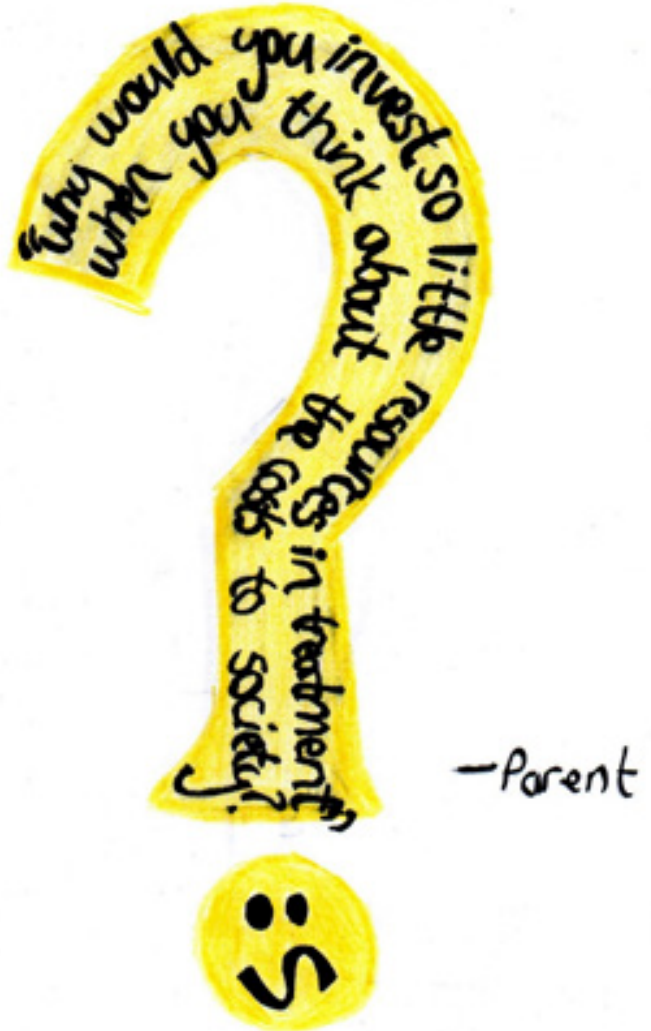

3.20 In 2012/13, NHS expenditure on child and adolescent mental health disorders was estimated to be $£ 700$ million (ie £0.70bn) or $6 \%$ of the total spend on mental health. Between 2006/7 and 2012/13, the proportion of mental health spending on children and young people has fallen.

3.21 NHS England is taking forward work on collecting comprehensive spending data on mental health services in the NHS. 


\section{NHS expenditure on mental health}

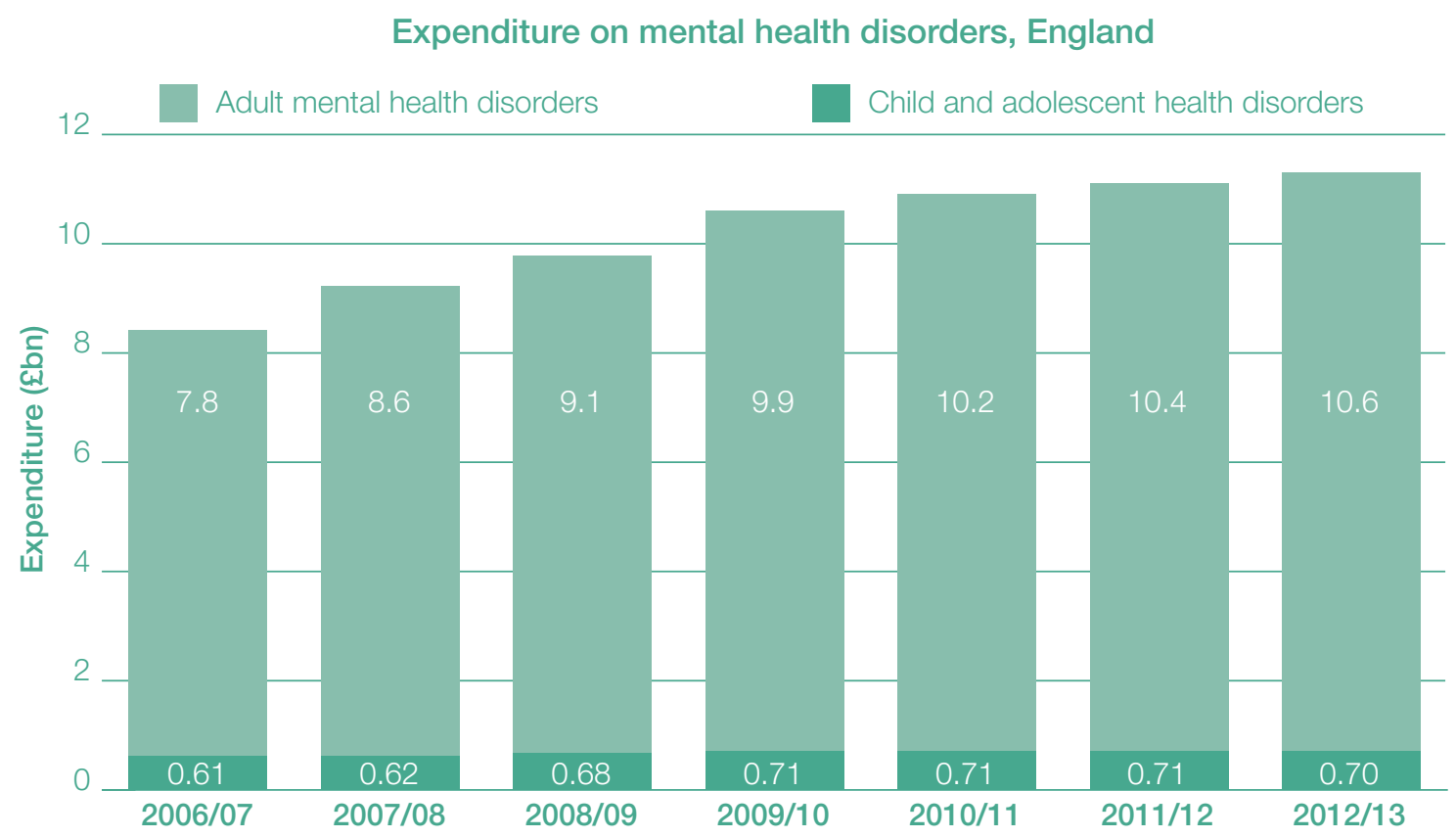

3.22 There is no national level information on current local authority social care or education spend on children and young people's mental health. However, from a number of surveys there would appear to be a pattern of increasing demand that local mental health services in many areas are struggling to meet.

3.23 The Department of Health and NHS England are working on improvements to overall mental health data and intelligence across the full life course.

\section{Issues to address}

\subsection{Evidence presented to and} discussions in the Taskforce have underlined the complexity and severity of the current set of challenges facing child and adolescent mental health services.

\subsection{These include:}

i. Significant gaps in data, information and system levers. There has been significant delay in national collection of outcomes metrics, access standards, development of payment and other incentive systems and their alignment across the health, education and social care systems, which are all critical to driving change in a co-ordinated way. Although there is locally collected data, there is a general lack of clarity about what is provided by whom, for what problem, for which child.

ii. Investment levels. The lack of data, information and system drivers have made Child and Adolescent Mental Health services (CAMHS) financially vulnerable. Historically, mental health services have suffered when the public sector is under financial pressure. NHS England and the Department of Health 
have initiated action to address this for health services for 2014/15 and 2015/16 but local government continues to face significant financial challenges and more work is needed.

iii. The treatment gap. The last UK epidemiological study ${ }^{32}$ suggested that, at that time, less than $25 \%-35 \%$ of those with a diagnosable mental health condition accessed support. There is emerging evidence of a rising need in key groups such as the increasing rates of young women with emotional problems and young people presenting with selfharm. In addition, there are some groups with additional vulnerabilities (see below) who, due to a range of issues, are not given the priority they need.

iv. Difficulties in access. NHS benchmarking data and recent audits reveal increases in referrals and waiting times, with providers reporting increased complexity and severity of presenting problems and a consequent rising length of stay in inpatient facilities. Since 2011, our best evidence is that these difficulties are the result of financial constraints accompanied by rising demand. ${ }^{33}$

V. Complexity of current commissioning arrangements. A lack of clear leadership and accountability arrangements for children's mental health across agencies with the potential for children and young

32 Green H, McGinnity A, Meltzer H, Ford T, Goodman R (2005). Mental health of children and young people in Great Britain, 2004. A survey carried out by the Office for National Statistics on behalf of the Department of Health and the Scottish Executive. Basingstoke: Palgrave Macmillan.

33 Department of Health (2013). Annual Report of the Chief Medical Officer 2013. Public Mental Health Priorities: Investing in the Evidence. London: Department of Health. people to fall though the net has been highlighted in numerous reports. ${ }^{34} \mathrm{Co}-$ ordination across the system, particularly for those children and young people with complex needs, is challenging where there is no lead agency accountable for the child or young person, despite the large number involved in providing services.

vi. Access to crisis, out of hours and liaison psychiatry services are variable. There are variations in access to appropriate or age-appropriate inpatient care close to home and available when needed. In some parts of the country, there is no designated health place of safety recorded by the CQC for under-18s.

\section{vii. Specific issues facing highly} vulnerable groups. All children and young people may experience adverse life events at some time in their lives, but some are more likely to develop mental health disorders eg following multiple losses and/or trauma in their lives, as a result of parental vulnerability or due to disability, deprivation or neglect and abuse. These children, young people and their families may find it particularly difficult to access appropriate services, or services may not be configured to meet their psychosocial needs. In addition, they sometimes find it more

34 National CAMHS Review (2008). Children and young people in mind: the final report of the National CAMHS Review. National CAMHS Review; HM Government (2011). No Health Without Mental Health: A cross-government mental health outcomes strategy for people of all ages. London: Department of Health; Department of Health (2012). Annual Report of the Chief Medical Officer 2012. London: Department of Health; CAMHS Tier 4 Report Steering Group (2014). CAMHS Tier 4 Report. London: NHS England. 
difficult to access services they may find alienating and may have a lifestyle that is not conducive to meeting regular appointments.

3.26 These issues are addressed in considering the key themes that form the basis of this report and the proposals it makes. 


\section{Promoting resilience, prevention and early intervention}

4.1 We need to value the importance of recognising and promoting good mental health and wellbeing in all people, not just focusing on mental illness and diagnosis. There is evidence that supporting families and carers, building resilience through to adulthood and supporting self-care reduces the burden of mental and physical ill health over the whole life course, reducing the cost of future interventions, improving economic growth and reducing health inequalities. ${ }^{35}$

4.2 It is therefore crucial that, locally, there is an integrated, partnership approach to defining and meeting needs. A wide range of professionals should be involved across universal, targeted and specialist services, through:

- promoting good mental wellbeing and resilience, by supporting children and young people and their families to adopt and maintain behaviours that support good mental health;

- preventing mental health problems from arising, by taking early action with children, young people and parents who may be at greater risk;

- early identification of need, so that children and young people are supported as soon as problems arise to prevent more serious problems developing wherever possible.

35 Annual Report of the Chief Medical Officer: Health in Scotland 2011, Transforming Scotland's Health (Chapter 3). Scottish Government: December 2012.

\section{Prevention and support from birth}

4.3 If we are to have the greatest chance of influencing the determinants of health and wellbeing, we should focus efforts on actions to improve the quality of care for children and families. We should start by making efforts to ensure a safe and healthy pregnancy, a nurturing childhood and support for families in providing such circumstances in which to bring up children.

4.4 There is a strong link between parental (particularly maternal) mental health and children's mental health. For this reason, it is as important to look after maternal mental health during and following pregnancy as it is maternal physical health. According to a recent study, maternal perinatal depression, anxiety and psychosis together carry a longterm cost to society of about £8.1 billion for each one-year cohort of births in the UK, equivalent to a long-term cost of just under $£ 10,000$ for every single birth in the country. ${ }^{36}$ Nearly three-quarters of this cost (72\%) relates to adverse impacts on the child rather than the mother. Some $£ 1.2$ billion of the long-term cost is borne by the NHS.

36 Bauer A, Parsonage M, Knapp M, lemmi V, and Adelaja B (2014). The costs of perinatal mental health problems. London: Centre for Mental Health. 


\section{Current action to improve early support for parents, carers and children from birth} (1 and 4)

- The Mandate between the Government and NHS England sets an objective to work with partner organisations to ensure that the NHS reduces the incidence and impact of postnatal depression through earlier diagnosis, and better intervention and support.

- The Mandate between Health Education England (HEE) and the Government recognises the importance of maternal mental health during pregnancy and after birth - by 2017, every birthing unit should have access to a specialist perinatal mental health clinician.

- The Institute for Health Visitors is updating training given to all health visitors around mental health and the Department of Health is working with HEE, the Royal College of Midwives and the Maternal Mental Health Alliance to design training programmes for midwives.

- Public Health England is publishing an update of the evidence base for the Healthy Child Programme ${ }^{37}$ (0-5 years) that will guide professionals including supporting early attachment between infant and parent(s).

- Ensuring progress with these mandate requirements and workforce capability will support better mental wellbeing for children and young people into the future. In addition, Achieving Better Access to Mental Health Services by 2020 sets out that $\mathrm{DH}$ and NHS England will consider developing an access and/or waiting standard for rapid access to mental health services for women in pregnancy or in the postnatal period with a known or suspected mental health problem.

- In the 2014 Autumn Statement to Parliament, the Chancellor announced a 0-2 year old early intervention pilot to prevent avoidable problems later in life. The Pilots will be run jointly by DfE and DH. They will complement the work of the Early Intervention Foundation, and link closely with other activity such as the Healthy Child Programme and the Troubled Families Programme. Details of how and where the pilots will operate will be made available shortly. Government will consider the emerging evidence in relation to prevention and intervening early with mental health problems.

4.5 The transfer of commissioning of 0-5 public health services to local government in October 2015 provides a great opportunity for local authorities, working through Health and Wellbeing Boards, to create a stronger focus on mental health in the early years and beyond. Public Health England's rapid review

37 Shribman S and Billingham K (2009). Healthy Child Programme - Pregnancy and the First Five Years of Life. London: Department of Health. of the evidence base for the Healthy Child Programme (0-5) will help local services make use of the most up-to-date evidence base.

4.6 There is strong evidence of the benefits of evidence-based parenting programmes in intervening early for children with behavioural problems. These are benefits to the individual child and family, as well as producing significant cost saving to the system as a whole. Such programmes should remain 
a priority for local authorities and better links developed with specialist services to work jointly on cases where families have difficulty engaging in groups or need intensive individual support before they are ready to join a group.

\section{The role of universal services in mental health promotion, prevention and early intervention}

\subsection{Universal services, including health visitors, Sure Start Children's Centres, schools, school health services including school nurses, ${ }^{38}$ colleges, primary care and youth centres, play a key role in preventing mental health problems. Universal services support children and young people's wellbeing through delivering mental health promotion and prevention activities, which work best when they operate on a whole- system basis.}

4.8 In our discussions with young people, they emphasised the difficulties many of them had faced in discussing their problems with their GP. Many of them also reported that their school was not an environment in which they felt safe to be open about their mental health concerns.

\subsection{For their part, GPs, schools and other} professionals such as social workers and youth workers often feel as frustrated as the children and their parents. They want to do the right thing, but have not necessarily been equipped to play their part or been provided with clear access routes to expertise and for referring to targeted and specialist support. Professionals working in child and adolescent mental health services are equally aware of the challenges that come from balancing identified need with available resource.

38 Chief Nursing Officer's Professional Leadership Team (2012). Getting it right for children, young people and families. London: Department of Health.
4.10 There is also a need for greater clarity about the core attributes that underpin mental health and resilience throughout life. The Department for Education is leading work to help schools ensure more pupils develop the character traits, attributes and behaviours, which, alongside academic achievement, underpin future success. The Department will work closely with all key stakeholders as this work develops, informed by insights and evidence on effective practice from its investment in character education projects and research, due in autumn 2016. Alongside this, Public Health England should continue to strengthen its work on core attributes that underpin mental health and resilience and the application of this by commissioners and service providers.

\section{GPs}

4.11 General Practice and the primary care team have an important part to play in supporting families, children and young people to develop resilience and in identifying and referring problems early. GPs take a holistic approach to the whole family registered with them and are responsible for primary physical and mental health. There is significant potential in that the GP practice is a less stigmatising environment than a mental health clinic. Many GPs have improved accessibility to young people by using the 'You're Welcome' standards and self-audit. ${ }^{39}$ Practices such as Herne Hill Group Practice in London, working with the voluntary sector organisation Redthread Youth, have gone further by creating the Well Centre with dropin clinics for young people where they can discuss a range of issues and have access to specialist mental health support.

39 Department of Health (2011). You're Welcome Quality criteria for young people friendly health services. London: Department of Health. 
4.12 There is also scope for GPs and other professionals with children and young people to consider referring for a wider range of interventions and services to support their mental health and wellbeing. The local offer could include commissioning approaches that support the ability for GPs to offer social prescribing, where activities such as sport are used as a way of improving wellbeing.

\section{Schools}

4.13 Many schools are already developing whole school approaches to promoting resilience and improving emotional wellbeing, preventing mental health problems from arising and providing early support where they do. Evidence shows ${ }^{40}$ that interventions taking a whole school approach to wellbeing have a positive impact in relation to both physical health and mental wellbeing outcomes, for example, body mass index (BMI), tobacco use and being bullied.

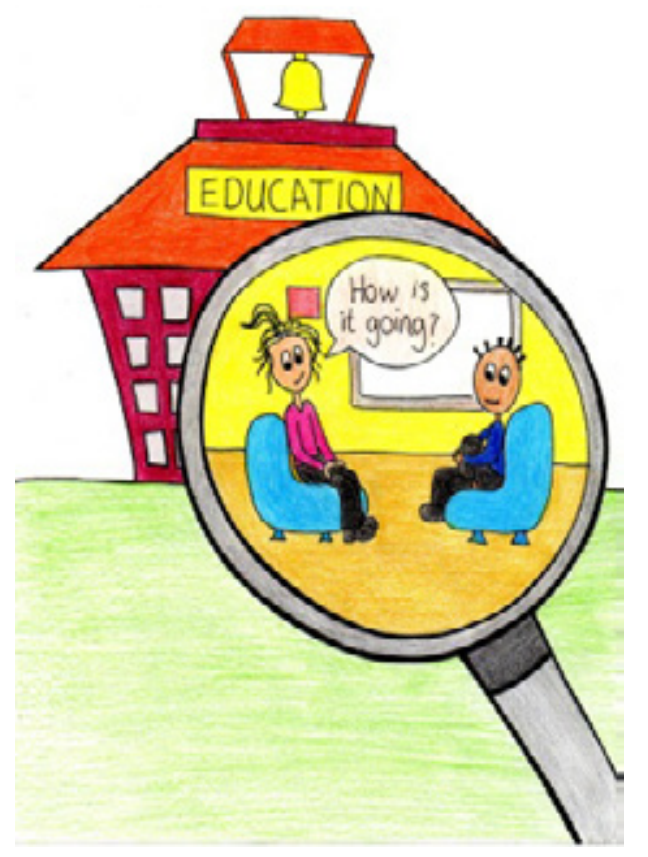

40 Brooks F (2012). Life stage: School Years. In: Annual Report of the Chief Medical Officer 2012. Our Children Deserve Better: Prevention Pays. London: Department of Health.
4.14 The vast majority of secondary schools surveyed in recent CentreForum research ${ }^{41}$ reported that they implement programmes to promote positive mental health universally across the student population, with 93\% doing this within the context of Personal, Social, Health, and Economic (PSHE) education. The research also indicates that pupils in $86 \%$ of secondary schools surveyed have access to a trained/qualified counsellor(s), and almost all secondary schools (98\%) have pastoral care services. While counselling services within schools are not intended as a substitute for other community and specialist mental health services, they can be a valuable complement to them.

\subsection{We encourage all schools (including} those in the independent sector) to continue to develop whole school approaches to promoting mental health and wellbeing (2). This will build on the Department for Education's current work on character building, PSHE and counselling services in schools (see box for details). The named mental health lead for schools proposed in chapter five would also make an important contribution to leading and developing whole school approaches.
$41 \quad$ Taggart H, Lee S, McDonald L (2014). Perceptions of wellbeing and mental health in English secondary schools: a cross sectional study. London: CentreForum Commission. 


\section{Current action to support schools in promoting resilience and prevention of mental health problems}

- The Department for Education (DfE) is leading work to improve the quality of teaching about mental health within Personal, Social, Health, and Economic (PSHE) lessons in schools, and has commissioned the PSHE Association to produce guidance for schools in teaching about mental health safely and effectively, which will be available in spring 2015. Alongside the guidance will be a series of lesson plans covering key stages 1-4 (5-16 year olds). For older pupils, they will address such topics as selfharm and eating disorders, as well as issues directly concerned with school life, such as managing anxiety and stress around exams.

- DfE is developing an evidence-based schools counselling strategy to encourage more and better use of counsellors in schools, with practical and evidence-based advice to ensure quality provision, that improves children's outcomes and achieves value for money. This will be published in spring 2015.

- DfE has invited schools, colleges and organisations to bid for a £3.5 million character education grant fund for local projects.

- School nurses lead and deliver the Healthy Child Programme (HCP) 5-19 and are equipped to work at community, family and individual levels. They can play a crucial role in supporting the emotional and mental health needs of school-aged children. School nursing services are universal and young people see them as nonstigmatising. ${ }^{42}$

- Inspection is a key lever to drive improvement. The new draft Ofsted inspection framework 'Better Inspection for All' includes a new judgement on personal development, behaviour and welfare of children and learners.

4.16 It is important that schools tackle bullying, including cyberbullying, robustly. The Government has continued to take action when required. By law, all schools must have a behaviour policy which includes measures to tackle all forms of bullying and they are held to account by Ofsted. The best schools create an ethos of good behaviour where pupils treat each other, and staff, with respect, understand the value of education, and appreciate the impact that their actions can have on others. The Department for Education has produced advice to help

42 Department of Health and Public Health England (2013). Promoting emotional wellbeing and positive mental health of children and young people. London: Department of Health. schools support pupils who are severely affected by bullying. ${ }^{43}$

4.17 Schools can help to contain cyberbullying during the school day by banning or limiting the use of personal mobile phones and other electronic devices. Schools also have the power to search for, and if necessary delete, inappropriate images (or files) on electronic devices, including mobile phones.
43 Department for Education (2013). Departmental advice on preventing and responding to bullying. London: Department for Education. 


\section{Developing a national conversation}

4.18 We need to create the space for an open national conversation about children and young people's mental health. Children, young people and their parents/carers need clearer awareness of what is good mental health and what is poor mental health, as well as better information about how to keep mentally and emotionally healthy.

4.19 To this end, the Taskforce proposed there could be a major national branded social marketing campaign with a mechanism for dialogue so it is a genuine two-way conversation - driven by children, young people, parents and carers (3). Options include building on the Time to Change campaign (www.time-to-change.org. uk/youngpeople) as well as looking for opportunities to address mental health and wellbeing issues with the Public Health England Rise Above ${ }^{44}$ campaign. The Time to Change programme has already been associated with greater mental health literacy as well as less stigmatising attitudes. ${ }^{45}$ In the last year or two, we have seen remarkable progress in reducing levels of stigma towards mental health conditions. It is now time we did the same for children and young people, to create a climate where there is as much interest in their emotional and cognitive development as there is in their academic development.

44 Public Health England (2014). Public Health England Marketing Strategy. London: Public Health England.

45 Evans-Lacko S, Malcolm E, West K, Rose D, London J, Rusch N, Little K, Henderson C, Thorniscroft G (2013). Influence of Time to Change's social marketing interventions on stigma in England 2009-2011. British Journal of Psychiatry 2012: 77-88.

\section{Harnessing digital technology}

\subsection{The digital world has become of} utmost importance with its potential to protect and enhance the mental health and wellbeing of our children and young people. We are raising a generation of 'digital natives' who differ from previous generations in the way they communicate. Electronic media has some positive influences, such as improved faster information processing; conversely, there are widespread concerns about potential negative effects, including decreased attention, hyperactivity, and excessive use. ${ }^{46}$ There is high risk that children and young people are subject to harmful exposure to inappropriate material, to the risks of cyber-bullying, to potential grooming and exploitation ${ }^{47}$ and to websites that reinforce negative behaviour, such as those encouraging excessive weight loss.

\subsection{We recognise there is already a} significant amount of work as part of the Government response on tackling child sexual exploitation as well as more broadly under the auspices of the National Group on Sexual Violence against Children and Vulnerable People. The need to influence and protect young people has a wide reach. Thus in the new computing programmes of study, which were introduced in September 2014, e-safety will be taught at all four key stages of school. It covers responsible, respectful and secure use of technology, as well as ensuring that pupils are taught age-appropriate ways of reporting any concerns they may have about what they see or encounter online.

46 Department of Health (2013). Annual Report of the Chief Medical Officer 2013. Public Mental Health Priorities: Investing in the Evidence. London: Department of Health.

47 National Crime Agency. CEOP Command. Available at: www.nationalcrimeagency.gov.uk/ about-us/what-we-do/child-exploitation-onlineprotection-ceop 
4.22 We also recognise the positive role of digital technology, which provides new opportunities to deliver the right information to children and young people and reduce stigma. For example, Mind has unveiled YouTube star and teen icon Zoe Sugg as its new Digital Ambassador, who has used her blog to share open and honest accounts of her own battles with anxiety and panic attacks, and launched the initiative \#DontPanicButton.

4.23 The use of apps and other digital tools can empower self-care, giving children and young people more control over their health and wellbeing and empowering their parents and carers. Harnessing the potential of the web to promote resilience and wellbeing aligns with the principles set out in Personalised Health and Care $2020^{48}$ and the priority it has already given to young people. Children and young people's mental health and wellbeing should be given the priority it deserves and the system should build on existing resources to support the intentions set out in this report - signalling the promise indicated by the National Information Board's Framework for Action.
4.24 We propose that the Government asks the National Information Board to work in close partnership with the Government Digital Service and young people themselves to develop a single framework for harnessing the power of digital technology and protecting young people from mental harm (5). Within this framework, we propose that Government considers incentivising the development of new apps and digital tools; and also whether there is a need for some form of kite-marking scheme based on research evidence to guide young people and their parents on quality.

$48 \quad$ National Information Board and Department of Health (2014). Personalised Health and Care 2020: using data and technology to transform outcomes for patients and citizens. London: Department of Health. 


\section{Resilience, prevention and early intervention for the mental wellbeing of children and young people - chapter 4 summary}

Our aim is to act early to prevent harm, by investing in the early years, supporting families and those who care for children and building resilience through to adulthood. Strategies should be developed in partnership with children and young people to support self-care. This will reduce the burden of mental and physical ill health over the whole life course.

Much of what is needed can be done now by:

1. Promoting and driving established requirements and programmes of work on prevention and early intervention, including harnessing learning from the new 0-2 year old early intervention pilots.

2. Continuing to develop whole school approaches to promoting mental health and wellbeing, including building on the Department for Education's current work on character and resilience, PSHE and counselling services in schools.

3. Building on the success of the existing anti-stigma campaign led by Time to Change, and approaches piloted in 2014/15, to promote a broader national conversation about, and raise awareness of mental health issues for children and young people.

With additional funding, a future government should consider:

4. Enhancing existing maternal, perinatal and early years health services and parenting programmes to strengthen attachment between parent and child, avoid early trauma, build resilience and improve behaviour by ensuring parents have access to evidencebased programmes of intervention and support.

5. Supporting self-care by incentivising the development of new apps and digital tools; and consider whether there is a need for a kitemarking scheme in order to guide young people and their parents in respect of the quality of the different offers. 


\section{Improving access to effective support - a system without tiers}

"You have to fit into their paths and none of their paths fit you."

"Mental health isn't a one size fits all treatment, it really depends on the person."

Young people who took part in the Taskforce engagement exercises.

\subsection{Our discussions with professionals} who work with children and young people revealed a strong, common theme - that it is essential that children and young people are at the heart of the work they do and the services that are provided for them. However, the tiers model, ${ }^{49}$ a reasonable construct at its inception in 1995, defines the system in terms of the services that provide the care. In practice, this means that children and young people have to fit the services, rather than the services fitting the changing needs of the child or young person.

\subsection{Furthermore, the tiers model has been} criticised for unintentionally creating barriers between services, embedding service divisions and fragmentation of care. It often results in children or young people falling in gaps between tiers and experiencing poor transitions between different services. At its worst, it can even lead to commissioners and providers of different tiers of service effectively passing the buck to one another.

49 The report on the Thrive model (see below) contains a description of the tiers model (page 5).
5.3 Many areas across the UK, such as Liverpool and Leeds, are already working to move away from the tiered structure by designing new local models which create a seamless pathway of care and support, and which address the need for the diversity of circumstances and issues with which families and young people approach mental health services. Alternative models can also be seen internationally. A further example of a more flexible needs-based model for structuring children and adolescent mental health services is the recently proposed 'Thrive model'. ${ }^{50}$ We consider this model to have potential and that it should be evaluated and debated further.

\subsection{The advantage of these models is that} they have the potential to move away from an inflexible and restrictive system, towards one which enables agencies to commission and deliver support to allow children and young people to move more easily between services and to make collaborative choices about what would work best for them at given points in time. It obliges providers to place expertise at the front end of delivery systems to establish with children, young people and families, the intervention most appropriate to their current need. However, it is also important to note that there is no

50 Wolpert M, Harris R, Jones M, Hodges S, Fuggle P, James R, Wiener A, Mckenna C, Law D, Fonagy P (2014). THRIVE: The AFC-Tavistock Model for CAMHS. London: CAMHS Press. Available at: www.tavistockandportman.nhs. uk/sites/default/files/files/Thrive\%20model\%20 for\%20CAMHS.pdf 
one size fits all. Models could and should be different in different types of locality; for example, a model which works well in rural Devon may fail to meet need if applied in inner-Manchester, and vice versa. This is why we have not dictated the local offer but been clear about the national ambition (6).

\section{Right time, right place, right offer}

"There needs to be one point of access between patients and services that the patient can approach to find out anything they wish to know about the rest of the services involved and out there."

A young person who took part in the Taskforce engagement exercises.

\subsection{The starting-point is that children and} young people and their parents/carers need clearer awareness of how to recognise when they might have a mental health problem as well as where and how to get help, clarity about what help is available, what might happen when they access it, and what to do while they are waiting.

5.6 Therefore, at the heart of any good local system should be cross-sector agreement to ensure clarity in respect of how services are accessed. Many areas are already using a single point of access to targeted and specialist mental health services through a multi-agency 'triage' approach, including areas working within the CYP IAPT programme such as Liverpool. There is a pressing need to develop these approaches more widely ( 7 and 16$)$. Common features of a single point of access system include:

- One point of contact for a wide range of universal services to access a team of children and young people's mental health professionals for advice, consultation, assessment and onward referral.

- Initial risk assessment to ensure children and young people at high risk are seen as a priority.

- Prompt decision-making about who can best meet the child/young person's needs (including targeted or specialist services, voluntary sector youth services and counselling services).

- Young people and parents are able to self-refer into the single point of access.

5.7 We propose the following to improve communication and access:

i. Create an expectation that there is a dedicated named contact point in targeted or specialist mental health services for every school and primary care provider, including GP practices (8 and 16). Their role would be to discuss and provide timely advice on the management and/or referral of cases, including consultation, co-working or liaison. This may include targeted or specialist mental health staff who work directly in schools/GP practices/voluntary sector providers with children, young people and families/carers.

ii. Create an expectation that there should be a specific individual responsible for mental health in schools, to provide a link to expertise and support to discuss concerns about individual children and young people, identify issues and make effective referrals (8 and 16$)$. This individual would make an important contribution to leading and developing whole school approaches.

iii. Develop a joint training programme for named individuals in schools and mental health services to ensure shared understanding and support effective communications and referrals (9). 
iv. Provide a key role for the voluntary and community sector to encourage an increase in the number of one-stopshop services, based in the community (7 and 16). They should be a key part of any universal local offer, building on the existing network of YIACS (Youth Information, Advice, and Counselling Services). Building up such a network would be an excellent use of any identified early additional investment. There may also be a case in future for developing national quality standards for a comprehensive one-stop-shop service, to support a consistent approach to improving outcomes and joint working.

v. Enable greater access to personal budgets for children and young people (and their families) who have a longer term condition or disorder, to give them more choice and control over when and how they access which services

vi. Ensuring there is a strategic link between children's mental health services and services for children and young people with special educational needs and disabilities (SEND) (10). This should be matched by involvement, where necessary, of mental health professionals in co-ordinated assessment and planning (for children and young people with and without Education, Health and Care Plans.)

\section{Use of standards}

\subsection{NHS England has committed to} developing access and waiting time standards in mental health. By 2020, the aim would be to provide a comprehensive set of access and waiting time standards that bring the same rigour to mental health as is seen in physical health services. This applies to children and young people who will benefit in the first year with the introduction of the first ever waiting time standards in respect of early intervention in psychosis. It is important that children and young people are taken fully into account as further access and waiting time standards are considered, subject to resource availability. Careful consideration will need to be given to which conditions are prioritised, working with experts, services and commissioners and building on current work to develop standards for eating disorders and the introduction of the standard for early intervention in psychosis. (17)

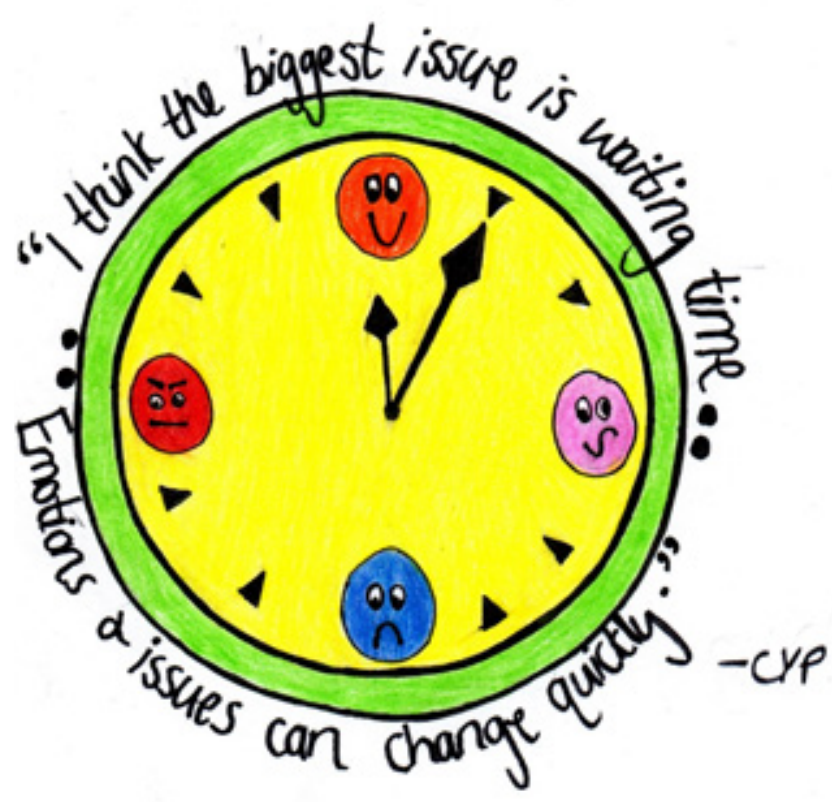

\section{A welcoming environment}

"The fact that they showed human qualities helped me feel comfortable sharing."

A young person who took part in the Taskforce engagement exercises.

5.9 There are some changes that have little cost which could be implemented straightaway. Examples include a warm 
and encouraging welcome for children, young people and parents/carers when they walk through the door; enabling and encouraging their involvement in their own treatment plans and reviews; having a positive attitude and culture within services and promoting effective participation. Young people say that these interactions make an enormous difference to how they feel, to their confidence in participating, and to counteracting the stigma associated with accessing mental health services.

5.10 Some children, young people and families find the formal setting of a clinic offputting and are unwilling to attend. This can lead to them saying that they do not wish to be referred or not turning up - particularly for some highly vulnerable groups, such as those involved with gangs or those who have been sexually exploited. As a consequence, some services experience high rates of children, young people and families not attending appointments. It is important that services monitor attendance and actively follow up families and young people who miss appointments and inform the referrer (see also paragraph 6.2). It may be necessary to find alternative ways to engage the child, young person or family.

5.11 Mental health practitioners and staff such as youth workers delivering interventions should follow existing good practice and give young people and families the choice to receive treatment away from traditional NHS mental health settings. This might mean that staff see them in public places, such as cafes and restaurants, or in schools, or homebased treatment and there are a number of areas where staff, including consultants, do so successfully. This may also help to reengage the young person with clinical staff and to be able to attend clinical settings at a later stage. This is likely to lead to a better result than young people or families failing to attend and receiving no support.

\section{Peer Support}

"Peer mentoring is a fantastic idea as young people should be able to feel like they aren't the only one going through these problems."

A young person who took part in the Taskforce engagement exercises.

\subsection{Young people, as well as parents or} carers, also have an important role to play in informing and supporting other young people and families about mental health prevention and access. Consultations carried out through YoungMinds' Engagement Survey and other engagement activities have shown that young people have a strong desire to hear from other young people who have accessed mental health services and CYP IAPT reports suggest this is also a priority for parents and carers. Peer support schemes should be led and designed by children and young people or by parents or carers, with careful professional support to reduce and manage risk both to peer mentors and the young people and families they are involved with. It is proposed that further work should be done with relevant education and third sector partners to audit where peer support is currently available and evaluate it, building on existing work such as the Royal Society for Public Health Youth Health Champions. Local areas can then consider closing gaps in provision. (11) 


\section{Digital access}

"I particularly like websites that have in depth resources on conditions and treatments eg Mind and Rethink. They talk about issues objectively so sufferers don't feel patronised, but also offer supportive information. They allow me to access information easily and whenever I want."

A young person who took part in the Taskforce engagement exercises.

\subsection{As we established in the previous} chapter, children and young people and many parents and carers are digitally literate and told us they wanted better and more use made of the web. This could be expressed in a number of ways, but must be informed by the views and preferences of children and young people to be effective. The Taskforce believes a future government should look at options enabling children, young people, parents and carers to access high quality and reliable online information and support. One such option could be a national branded web based portal established using NHS Choices, in line with the recently published National Information Board framework. ${ }^{51}$ (18) It could build on the successful MindEd website (www.minded.org.uk) aimed at professionals to provide national information about mental health and wellbeing in an engaging and reliable format. The NHS Choices content on adult mental health should link to the children and young people equivalent - the Youth Wellbeing Directory (youthwellbeingdirectory. com) and services are encouraged to register with the Directory.

$51 \quad$ National Information Board and Department of Health (2014). Personalised Health and Care 2020: using data and technology to transform outcomes for patients and citizens. London: Department of Health.

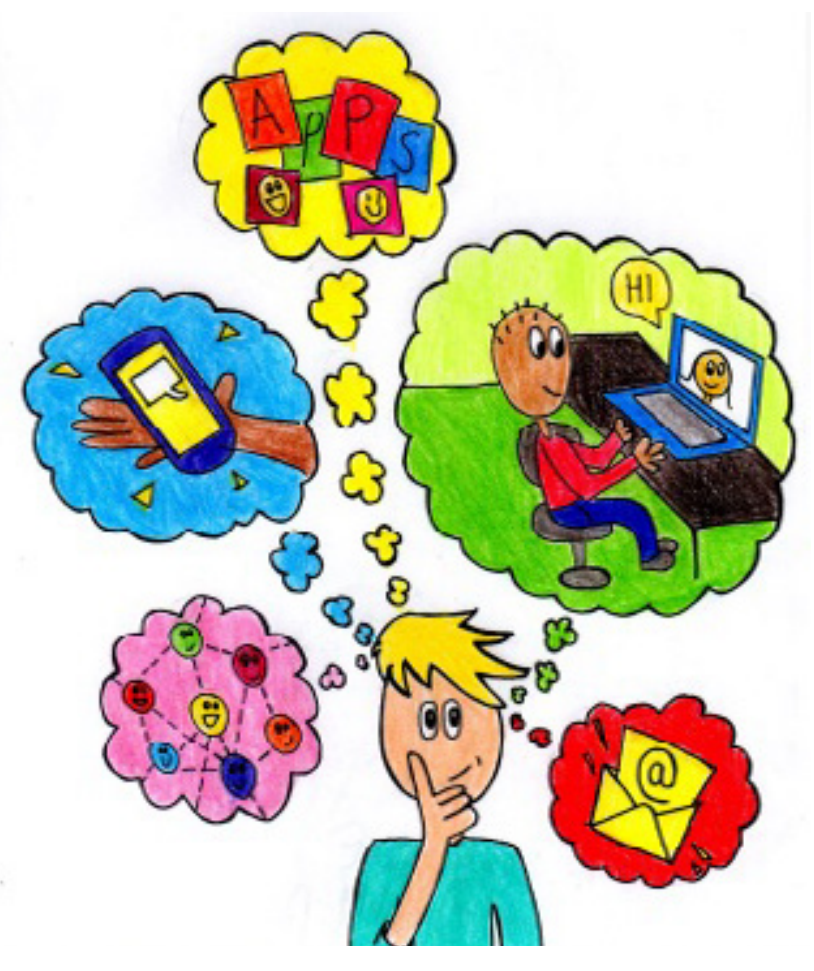

\section{Community mental health} provision

5.14 The availability and adequacy of the right mix of specialist community health services is critical to the success of THRIVE and similar needs based 'triage' models. Under these models, community mental health is not just a set of services to be referred into. It becomes a joined-up team, working proactively to support other professionals in their settings as well as managing caseloads in terms of higher level interventions. This can identify children and young people who may not present until they are in crisis at an early stage and improve support after discharge.

5.15 The shape and structure of these local teams cannot be defined at national level. However, national agencies can help by providing tools and best practice guidance which enable commissioners and providers to work together to assess the capacity and 
capability they require, and to enable efficient and effective prioritisation of resources, for example via www.chimat.org.uk.

\section{Dealing with crisis}

5.16 The litmus test of any local mental health system is how it responds in a crisis. For children and young people experiencing mental health crisis, it is essential that they receive appropriate support/intervention as outlined in the Crisis Care Concordat, ${ }^{52}$ including an out-of-hours mental health service (12). The challenge of supporting a child or young person in a crisis includes ensuring that there is a swift and comprehensive assessment of the nature of the crisis. There are examples around the country of dedicated home treatment teams for children and young people, but these are not universally available. Some children and young people end up in A\&E, where access to appropriate and timely psychiatric liaison from specialist child and adolescent mental health services is not always available. Some are placed (not always appropriately) on paediatric or general adult hospital wards. The national development of all-age liaison psychiatry services in A\&E Departments with targeted investment over this and the next financial year, as set out in the joint Department of Health and NHS England publication, Achieving Better Access to Mental Health Services by 2020, should mean that appropriate mental health support in A\&E is more readily available. This needs to be carefully monitored.

5.17 For some children and young people, their route into specialist services is more extreme and is through detention by the

52 Department of Health and Concordat signatories (2014). Mental Health Crisis Care Concordat Improving outcomes for people experiencing mental health crisis. London: Department for Health. police, under Section 136 of the Mental Health Act. Those who exhibit such distress and risk to themselves or others that a section 136 detention becomes warranted will need further support, which may not be purely from mental health services. There is broad support for legislating to ensure that no child or young person under-18 would be detained in a police cell as a place of safety, subject to there being sufficient alternative places of safety. ${ }^{53}$ (19) It is also important to develop improved data on the availability of crisis/home treatment for under-18 year olds and the use of section 136 for children and young people under-18 to support better planning. CQC should be asked to carry out routine assessments of places of safety with a focus on their age-appropriateness for children and young people.

\section{Inpatient care}

5.18 While community-based mental health services have a significant role in supporting children and young people in great need, there will always be some children and young people who require more intensive and specialised inpatient care. These must be age-appropriate and as close to home for the child or young person as possible.

5.19 The access and utilisation of specialised beds is a signal of how the whole system is working and therefore cannot be addressed in isolation. As the recent NHS England Tier 4 review $^{54}$ has demonstrated, there have been gaps in provision that NHS England is addressing. The key to commissioning the right type of care, in the right places is to adopt a whole system

53 Department of Health and Home Office (2014). Review of the Operation of Sections 135 and 136 of the Mental Health Act 1983. London: Department of Health and Home Office.

54 CAMHS Tier 4 Report Steering Group (2014). CAMHS Tier 4 Report. London: NHS England. 
commissioning perspective compatible with the type of model we describe in this chapter. This should address the role of pre-crisis, crisis, and 'step-down' services alongside inpatient provision. We return later in the report to the question of how we achieve a planning and commissioning framework, and information systems that can enable the system to make much better decisions about what inpatient capacity is required and to improve outcomes for children and young people for whom inpatient care cannot be avoided. There is strong support for investing in effective targeted and specialist community provision, including admission prevention and 'step-down' provision. This can provide clear pathways for young people leaving inpatient care to help avoid unnecessary use of inpatient provision and shorten duration of stay by easing the transition out of inpatient care (13). In line with the NHS 5 Year Forward View, NHS England is exploring a range of options for future commissioning and more collaborative work.

\section{Use of residential care}

\subsection{If we are to improve outcomes for} young people, especially those with learning disabilities, we must all learn from the lessons arising from the terrible events at Winterbourne View hospital, as to how people can become institutionalised. Children and young people with challenging behaviour can too easily be admitted to residential care unsuited to supporting their long-term health and wellbeing, and which does not support preparation for transition to adulthood and independent living. This is a group of vulnerable children and young people who already face the poorest outcomes, both in terms of their health and long-term independence and security. Sir Stephen Bubb's recent report highlighted the specific pressures which combine to force a young person into a residential setting: the lack of awareness of the individual's needs and wishes; the complexity of joint commissioning to deliver service transformation; the absence of viable alternative community-based provision; and the resource issues which inhibit its development. ${ }^{55}$

\subsection{As highlighted in the Government's} response to the Bubb report, in 2015/16 NHS England will lead partners in developing ways to strengthen the assurance that an admission is the best approach to care. This work will involve people with learning disabilities and their families and include:

- robust admission gateway processes for those with learning difficulties;

- a challenge process to check that there is no alternative to admission; and

- the agreement of a discharge plan on admission. ${ }^{56}$

\subsection{Children and young people's} mental health services must draw on this methodology and apply similar principles.

5.23 There are likely to be some children and young people with mental health needs, usually those at risk of crisis, for whom an inpatient setting will be the most suitable. The effectiveness of care provided to children and young people in crisis can be assessed by the extent to which it meets their immediate needs, whilst providing a basis for long term support and improvement. There should be systemic safeguards in place to prevent it becoming their permanent home which include:

55 Transforming Care and Commissioning Steering Group (2014). Winterbourne View - Time for Change. Transforming the commissioning of services for people with learning disabilities and/ or autism. London: ACEVO.

$56 \quad$ NHS England (2015). Transforming Care for People with Learning Disabilities - Next Steps. London: NHS England. 
i. ongoing strategic audits of admissions;

ii. a co-ordinated outcome focused care plan for each inpatient (this could be part of an Education, Health and Care plan where the child was eligible because of their learning disability);

iii. regular, comprehensive reviews of the suitability of the placement, against criteria focused on transition outcomes for the child or young person; and

iv. engagement with the young person and their family.

\section{Managing transitions}

"I had a very bad transition from CAMHS to adult services. One day I was in CAMHS with plenty of support and then the next, the only support I knew of was a crisis number. It took over 6 months for me to have a proper assessment and be assigned a care co-ordinator, by which time I had suffered a complete relapse in my condition."

A young person who took part in the Taskforce engagement exercises.

\subsection{The issue of transition for young} people is longstanding, but focusing on a moment in time masks the real issue, which is how we ensure better co-ordination of mental health services for young adults.

5.25 All young people face multiple and often simultaneous transitions as they move to adulthood. This can be from school to higher or further education or work. They may be in the process of leaving home or care. The families of those in the armed forces may be particularly affected by multiple moves. Young people transferring from children and young people's mental health services differ from those leaving physical services in that, for many, adult mental health services are either not available or not appropriate. Adult mental health services are not universally equipped to meet the needs of young people with conditions such as ADHD, or mild to moderate learning difficulties or autistic spectrum disorder.

5.26 For some young people, the nature of adult mental health services and their emphasis on working with the individual rather than a more holistic approach including the family means that young people prematurely disappear from services altogether despite needing further support. ${ }^{57,58}$

\subsection{Youth Information Advice and} Counselling Services (YIACs) usually operate over the age of transition, often up to the age of 25. We also note that in some parts of the country, such as Birmingham and Norfolk, there is a move to develop mental health services for 0-25 year olds. This new development will be watched with considerable interest.

\subsection{The key components of best practice} transition which are valued by both young people and clinicians should be built into Joint Strategic Needs Assessments (JSNAs), joint strategies for young people's and adult services and into all contracts between commissioners and providers of

57 Singh SP, Paul M, Ford T, Kramer T, Weaver $T$ (2008). Transitions of Care from Child and Adolescent Mental Health Services to Adult Mental Health Services (TRACK Study): A study of protocols in Greater London. BMC Health Services Research 8: 135.

58 McLaren S, Belling R, Paul M, Ford T, Kramer T, Weaver T, Hovish K, Islam Z, White S, Singh SP (2013). 'Talking a different language': an exploration of the influence of organizational cultures and working practices on transition from child to adult mental health services. BMC Health Services Research 13: 254. 
young people's and adult services. ${ }^{59,60,61}$ NHS England has published a model specification $^{62}$ based on best practice for transitions and a transfer/discharge protocol that can be used by local areas to support better transition planning and delivery.

\subsection{The Taskforce does not wish to be} prescriptive about the age of transition, but does recognise that transition at 18 will often not be appropriate. We recommend flexibility around age boundaries, in which transition is based on individual circumstances rather than absolute age, with joint working and shared practice between services to promote continuity of care. (15)

5.30 Vulnerable young people, such as care leavers and children in contact with the youth justice system, may also be especially vulnerable at points of transition and local strategic planning on transition should take their needs into account.
59 Joint Commissioning Panel for Mental Health (2012). Guidance for commissioners of mental health services for young people making the transition from child and adolescent to adult services. UK: Joint Commissioning Panel for Mental Health.

60 Hovish K, Weaver T, Islam Z, Paul M, Sing SP (2012). Transition Experiences of Mental Health Service Users, Parents, and Professionals in the United Kingdom: A Qualitative Study. Psychiatric Rehabilitation Journal 35(3): 251-257.

61 McLaren S, Belling R, Moli P, Ford T, Kramer T, Weaver T, Hovish K, Islam Z, White S, Singh SP (2013). 'Talking a different language': an exploration of the influence of organizational cultures and working practices on transition from child to adult mental health services. BMC Health Services Research 13: 254.

62 NHS England. Resources for CCGs. Available at: www.england.nhs.uk/resources/resources-forccgs/
"My university GP was wonderful and made the effort to contact my GP at home, along with former services I had used for treatment, to get full information on my history of mental health problems... this is the experience that I think everyone should be having."

A young person who took part in the Taskforce engagement exercises

5.31 We also acknowledge the difficulty of transitions for university students as having extra complexity due to geographical relocation and transience of residence.

Students may need access to mental health support both at home and at university, both from primary and secondary care services. We support the production of best practice guidance for CCGs and GPs around student transitions which encourages close liaison between the young person's home-based and university-based primary care teams and promotes adherence to NHS guidelines on funding care for transient populations. 


\section{Improving access to effective support - chapter 5 summary}

Our aim is to change how care is delivered and build it around the needs of children and young people and families. This means moving away from a system of care defined in terms of the services organisations provide to ensure that children and young people have easy access to the right support from the right service at the right time.

Much of what is needed can be done now by:

6. Moving away from the current tiered system of mental health services to investigate other models of integrated service delivery based on existing best practice.

7. Enabling single points of access and One-Stop-Shop services to increasingly become a key part of the local offer, harnessing the vital contribution of the voluntary sector.

8. Improving communications and referrals, for example, local mental health commissioners and providers should consider assigning a named point of contact in specialist children and young people's mental health services for schools and GP practices; and schools should consider assigning a named lead on mental health issues.

9. Developing a joint training programme to support lead contacts in specialist children and young people's mental health services and schools.

10. Strengthening the links between children's mental health and learning disabilities services and services for children and young people with special educational needs and disabilities (SEND).

11. Extending use of peer support networks for young people and parents based on comprehensive evaluation of what works, when and how.

12. Ensuring the support and intervention for young people being planned in the Mental Health Crisis Care Concordat are implemented.

13. Implementing clear evidence-based pathways for community-based care, including intensive home treatment where appropriate, to avoid unnecessary admissions to inpatient care.

14. Include appropriate mental health and behavioural assessment in admission gateways for inpatient care for young people with learning disabilities and/or challenging behaviour.

15. Promoting implementation of best practice in transition, including ending arbitrary cutoff dates based on a particular age.

With additional funding, a future government should consider:

16. Improving communications, referrals and access to support through every area having named points of contact in specialist mental health services and schools, single points of access and one-stop-shop services, as a key part of any universal local offer.

17. Putting in place a comprehensive set of access and waiting time standards that bring the same rigour to mental health as is seen in physical health services.

18. Enabling clear and safe access to high quality information and online support for children, young people and parents/carers, for example through a national, branded web-based portal.

19. Legislating to ensure no young person under the age of 18 is detained in a police cell as a place of safety. 


\section{Care for the most vulnerable}

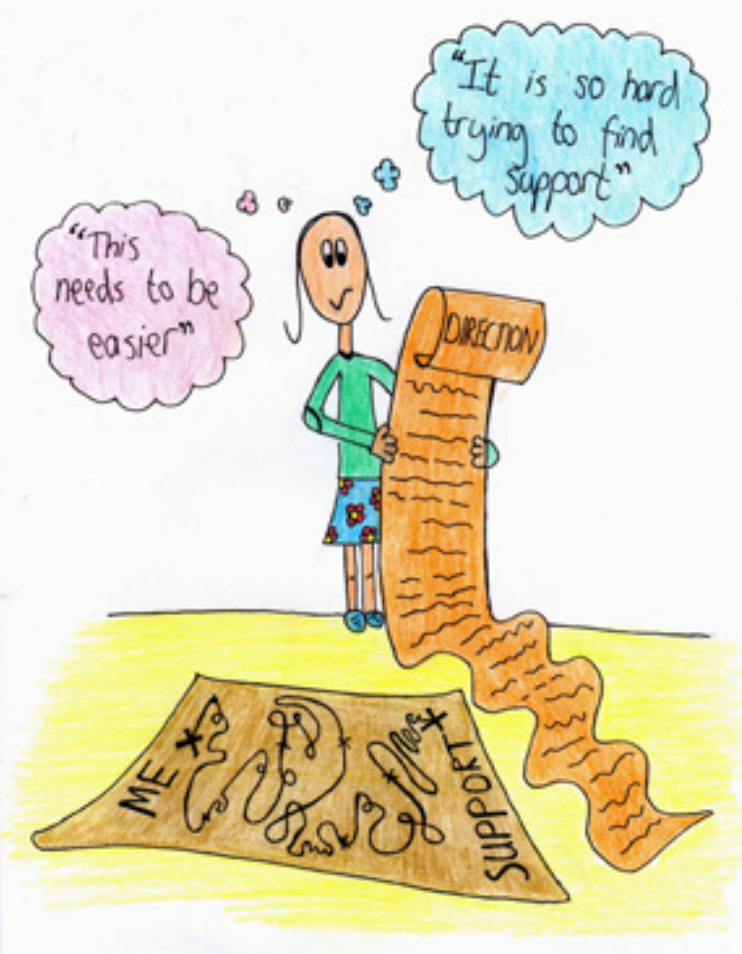

6.1 There are some children and young people who have greater vulnerability to mental health problems but who find it more difficult to access help. If we can get it right for the most vulnerable, such as looked-after children and care leavers, then it is more likely we will get it right for all those in need.

\subsection{The aim is to support staff who work} with vulnerable groups by providing access to high quality mental health advice when and where it is needed. Co-ordinated services should be provided in ways in which children and young people feel safe, build their resilience, so that they are offered evidencebased interventions and care, drawing on the expertise and engagement of all the key agencies involved. Children, young people and their families who have additional vulnerabilities and complex mental health needs should not have to fight for services, nor be offered services that are well-meaning, but are not evidence-based or which fail to meet their needs. The Taskforce members heard of cases where, if vulnerable young people had been able to access specialist advice and support more rapidly, it would have resulted not only in earlier and better outcomes, but also a significant saving to the public purse. In addition, not attending appointments should not lead to a family or young person being discharged from services, but should be considered as an indicator of need and actively followed up (this can apply to all children and young people see also paragraph 5.10) (20).

\section{A flexible, integrated system to meet the needs of vulnerable children and young people}

6.3 Mental health services need to work effectively within and in partnership with existing service delivery structures to help vulnerable children and young people - such as Early Help Services, services for Troubled Families, Child Protection and Safeguarding Services, as well as education, youth justice services and Multi-Agency Safeguarding Hubs. Staff in mental health services need to utilise and build on existing opportunities where agencies are already working with the child - for instance, looked-after care review meetings, child protection case conferences 
or youth justice assessments and the Common Assessment Framework.

6.4 There is a clear need for appropriate and bespoke care pathways that incorporate new models of providing effective, evidencebased interventions to vulnerable children and young people to provide a social and clinical response to meeting their needs (21). The provision of mental health support should not be based solely on clinical diagnosis, but on the presenting needs of the child or young person and the level of professional or family concern (22). Some children and young people will benefit from services which tackle problems across all family members, including adult mental health, substance misuse issues or complex cases that do not have a clear clinical diagnosis.

6.5 The most effective multi-agency arrangements have in place a clear sense of purpose shared by all agencies, together with shared assessment, case management and regular multi-agency case review processes overseen by multi-agency governance boards. The fact that mental health support is required does not necessarily mean that it is mental health services that are responsible overall for managing the case.

\section{Trauma-focused care}

\subsection{Experiencing or witnessing violence} and abuse or severe neglect has a major impact on the growing child and on long term chronic problems into adulthood. Many mental health service users of all ages have problems directly attributable to severe neglect and/or trauma in the early years. Some vulnerable children and young people - including those who are adopted, lookedafter children, those in contact with the youth justice system and substance misusing young people - are more likely to have been affected during childhood and adolescence.
6.7 Enhanced training for staff working with children and young people would lead to greater professional awareness of the impact of trauma, abuse or neglect on mental health (27). This should be coupled with effective treatment, including:

- Ensuring assessments carried out in specialist services include sensitive enquiry about neglect, violence and physical, sexual or emotional abuse. For young people aged 16 and above, as part of the Government's response to the concerns arising about child sexual exploitation, routine enquiry in line with NICE guidelines ${ }^{63}$ (whereby every young person is asked during the mental health assessment about violence and abuse) will be introduced from 2015-164 (23).

- Those children and young people who have been sexually abused and/or exploited should receive a comprehensive specialist initial assessment, and referral to appropriate services providing evidence-based interventions according to their need. There will be a smaller group who are suffering from a mental health disorder, who would benefit from referral to a specialist mental health service (24).

- Specialist services for children and young people's mental health should be actively represented on Multi-Agency Safeguarding Hubs which should be used more extensively to identify those at high risk who would benefit from referral at an earlier stage (25).

63 National Institute for Health and Care Excellence (2014). NICE public health guidance 50. Available at: www.nice.org.uk/guidance/ph50/

64 Casey $L$ (2015). Report of inspection of Rotherham metropolitan borough council. London: Department for Communities and Local Government. 


\section{Delivering care to vulnerable groups}

\subsection{There are some specific models of} provision that the Taskforce considered to be particularly helpful to these groups. Whatever models are adopted, the professionals involved need to specifically address the need to seek out, listen to, and respond to the voices of vulnerable children and young people.

\section{A consultation and liaison mental health model:}

\subsection{Applying an approach whereby} specialist services are available to provide advice, rather than to see those who need help directly to advise on concerns about mental health or neurodevelopmental difficulties is already best practice in some areas, for some very specific and highly vulnerable groups. Consultation and liaison teams can be used to help staff working with those with highly complex needs which include mental health difficulties - such as those who have been adopted or those with harmful sexual behaviour, and those in contact with the youth justice system - based on the complexity of the issues involved. These services would offer advice, troubleshooting, formal consultation and care planning, or assessment and intervention in cases where this is required above and beyond the level of existing cross-agency provision (including specialist services). There would need to be an identified specialist point of reference, including a senior clinician with specific expertise within mental health services. The roll-out of such teams could be piloted and, if successful, implemented at a sub-regional level (28).

\section{Embedding mental health practitioners in teams responsible for groups of vulnerable children and young people}

6.10 Young people who are amongst the most excluded from society, such as those involved in gangs, those who are homeless and/or looked-after children, need support from people they trust. This is a small number of young people, who may not even recognise that they have mental health problems. They benefit from having a mental health practitioner embedded in teams that have relationships with, and responsibility for such groups, such as a youth club or hostel (29). The embedded worker can develop a relationship with the young people through youth-led activities so that they are then able to respond as a familiar, trusted adult as the need arises, working with more specialist or intensive services as required. They can also impart basic mental health skills to frontline staff. This approach has been successfully developed by MAC-UK's INTEGRATE model (see www.mac-uk.org) which also incorporates the necessary governance structures essential for success. INTEGRATE requires a highly flexible team structure which includes the regular mapping of each young person's needs, informing a consistent and psychologically-informed approach across the team members.

6.11 A case study, Jay's story, highlighting this approach and the value of a familiar, trusted professional in engaging the most vulnerable and difficult to reach children and young people is set out in the Vulnerable Groups and Inequalities Task and Finish group report. 


\section{Designated professionals}

"We need services that understand we need to stick with young people who DNA and assertively engage them, instead of being pushed to close cases due to pressures on throughput. We also need services that can be responsive to risk and windows of opportunity for engagement, and to use these for long term work"

A CAMHS psychologist who took part in the Taskforce engagement exercises.

"I should be able to reach out to someone in any of the settings when I need, but for it all to be coordinated by one person."

A young person who took part in the Taskforce engagement exercises.

\subsection{Children and young people in} vulnerable groups are amongst the most complex seen in specialist services. Systems such as appointing a lead professional through a Common Assessment Framework (CAF), Team Around the Child or Family, or the Care Programme Approach (for those with severe mental health problems) already exist in many places. For some, the consistent application of these needs to be improved - particularly for vulnerable children and young people with complex needs who require care that is well-planned and coordinated with information shared effectively. A designated or lead professional should be identified and their role strengthened someone who knows the family well - to liaise with all agencies and ensure that services are targeted and delivered in an integrated way (26). This role could be allocated through a number of multi-agency processes, including the CAF or Team Around the Child or Family processes.
6.13 The decision about which plan to use will depend on the needs of the child and family, but the lead professional or Care Co-ordinator's role is to co-ordinate support and services from across agencies to meet the needs, for example, of children and young people in contact with the youth justice system, whose care may otherwise fall between several different agencies. For young people with more severe mental health difficulties or those transitioning to adult mental health services, the Care Programme Approach may be the most appropriate approach. ${ }^{65}$

\section{Reducing Health Inequalities and Promoting Equality}

\subsection{The Taskforce was told that some} groups, for example, learning disabled children find it difficult to access specialist services. In addition, studies have shown marked health inequalities in relation to children and young people's mental health, with correlations between poor mental health and disadvantage - for example, children in low income families having a threefold increased risk of developing mental health problems. ${ }^{66}$ We know that improving children and young people's mental health and their access to mental health services will require solutions that are tailored to the needs of children and young people from all backgrounds, of all characteristics, and from all sectors of the community.

65

Department of Health (2008). Refocusing the Care Programme Approach - Policy and Positive Practice Guidance. London: Department of Health.

66 Green H, McGinnity A, Meltzer H, Ford T, Goodman R (2005). Mental health of children and young people in Great Britain, 2004. A survey carried out by the Office for National Statistics on behalf of the Department of Health and the Scottish Executive. Basingstoke: Palgrave Macmillan. 
6.15 The Equality Act 2010 requires all public and voluntary sector organisations to have due regard to the need to eliminate discrimination, advance equality of opportunity and foster good relations between different people. In addition, the Health and Social Care Act 2012 introduced duties on the Secretary of State for Health, NHS England and on CCGs to have regard to the need to reduce health inequalities. ${ }^{67}$

6.16 For NHS England and CCGs, the health inequalities duties mean they must consider the need to reduce inequalities in access and outcomes for patients. In meeting these duties, they will wish to demonstrate that they have considered how policies and services for children and young people vulnerable to, or receiving support for, mental health problems take account of need, not just demand, and give appropriate focus to those groups in the population which have poorer access or outcomes.

6.17 Whilst the health inequalities duties apply only to the Health Secretary and NHS, the Taskforce encourages all those involved in commissioning mental health and wellbeing services for children and young people to give the same consideration to the need to reduce health inequalities in access and outcomes (21).

\section{Caring for the most vulnerable - chapter 6 summary}

Current service constructs present barriers making it difficult for many vulnerable children, young people and those who care for them to get the support they need. Our aim is to dismantle these barriers and reach out to children and young people in need.

Much of what is needed can be done now by:

20. Making sure that children, young people or their parents who do not attend appointments are not discharged from services. Instead, their reasons for not attending should be actively followed up and they should be offered further support to help them to engage. This can apply to all children and young people.

21. Commissioners and providers across education, health, social care and youth justice sectors working together to develop appropriate and bespoke care pathways that incorporate models of effective, evidence-based interventions for vulnerable children and young people, ensuring that those with protected characteristics such as learning disabilities are not turned away.

22. Making multi-agency teams available with flexible acceptance criteria for referrals concerning vulnerable children and young people. These should not be based only on clinical diagnosis, but on the presenting needs of the child or young person and the level of professional or family concern.

23. Mental health assessments should include sensitive enquiry about the possibility of neglect, violence and abuse, including child sexual abuse or exploitation and, for those aged 16 and above, routine enquiry, so that every young person is asked about violence and abuse.

$67 \quad$ Equality and Health Inequalities Team (2014).

Guidance for NHS commissioners on equality

and health inequalities legal duties. Leeds: NHS

England. 
24. Ensuring those who have been sexually abused and/or exploited receive a comprehensive assessment and referral to appropriate evidence-based services. Those who are found to be more symptomatic who are suffering from a mental health disorder should be referred to a specialist mental health service.

25. Specialist services for children and young people's mental health should be actively represented on Multi-Agency Safeguarding Hubs to identify those at high risk who would benefit from referral at an earlier stage.

26. For the most vulnerable young people with multiple and complex needs, strengthening the lead professional approach to co-ordinate support and services to prevent them falling between services.

With additional funding, a future government should consider:

27. Improving the skills of staff working with children and young people with mental health problems by working with the professional bodies, NHS England, PHE and HEE, to ensure that staff are more aware of the impact that trauma has on mental health and on the wider use of appropriate evidence-based interventions.

28. Piloting the roll-out of teams specialising in supporting vulnerable children and young people such as those who are looked after and adopted, possibly on a sub-regional basis, and rolling these out if successful.

29. Improving the care of children and young people who are most excluded from society, such as those involved in gangs, those who are homeless or sexually exploited, looked-after children and/or those in contact with the youth justice system, by embedding mental health practitioners in services or teams working with them. 


\section{Accountability and transparency}

7.1 We have a wealth of information and many examples across the country of services moving towards greater integration and offering greater choice of evidence-based outcomes focused treatments working collaboratively with children and young people. However, this is not consistent and there is unacceptable variation.

\subsection{Agreeing better models of care is} not enough. Right now there are too many barriers to have confidence that such models would succeed because:

- the system of commissioning services is fragmented, with money often sitting in different budgets, in different organisations, in different parts of the system and without clear lines of accountability;

- there is limited access to the necessary information to know how a local system is working in respect of access and waiting times, how outcomes are achieved or if they provide value for money;

- there is poor information sharing within the system which hampers joint working; and

- the best practice standards, agreed as quality markers for accreditation systems, are not universally applied.

7.3 These are ingrained and systemic problems facing children and young people's mental health services that require strong leadership right across the whole system and at every level.
7.4 The recent changes to the national statutory framework for children and young people with special educational needs and disabilities (SEND) establish a platform for significant potential improvements over time for a cohort which includes some children and young people in need of mental health services. It is not possible to simply copy this model in respect of mental health, as support and treatment are quite different, but there are key features that are relevant:

- access to a wider range of local services through a transparent 'local offer';

- clarity over points of access and decision-making processes for more specialist support, including use of triage processes;

- co-ordination of assessment and planning around the individual child, involving all relevant services, facilitated by information sharing and a lead professional or key worker; and

- giving young people and parents more control, including greater use of personal budgets.

\section{Securing the best possible service for children and young people with mental health problems}

7.5 We consider that there are a number of issues that need to be addressed in the organisational and accountability frameworks if we are to achieve transformation in the service offer. 
7.6 There was strong support from many members of the Taskforce to make it a requirement at the local level for there to be a lead accountable commissioning body to co-ordinate commissioning and the implementation of evidenced-based care (30). Many members of the Taskforce also favour the creation of a single, separately identifiable budget for children's mental health services. These proposals build on the learning from those areas which are already jointly commissioning children's mental health services between Clinical Commissioning Groups and local authorities, in some cases with pooled budgets. We envisage in most cases the CCG would establish lead commissioning arrangements working in close collaboration with local authorities. We also recognise the need for flexibility to allow different models to develop to suit local circumstances and would not want to cut across alternative arrangements.

"If we are all working towards the same outcomes, planning in an integrated way to meet them, using clear accountability structures and a person-centred planning approach, then joint ownership of outcomes is inevitable. This is not easy to do - but... we can start."

A community services manager who took part in the Taskforce engagement exercises.

7.7 There is a need to address the ambiguity in local authorities' role and responsibilities in respect of child mental health commissioning. Although the statutory lever under the Children Act 1989 remains in place, along with responsibilities regarding lookedafter children and care leavers, the financial position that local authorities are facing is challenging and there is no longer any ring-fenced budget for this provision within local authorities. As a result, we are seeing very different patterns of commitment and contribution across both public health and children's social care budgets. At the least, there should be full transparency in terms of individual local authorities' contribution.

7.8 The work of the lead commissioner should be based upon an agreed local plan for child mental health services, agreed by all relevant agencies and with a strong input from children, young people and parents/ carers (30). The local plan itself should be derived from the local Health and Wellbeing Strategy which places an onus on Health and Wellbeing Boards to demonstrate the highest level of local senior leadership commitment to child mental health. Health and Wellbeing Boards have strategic oversight of the commissioning of the whole pathway or offer regarding children and young people's mental health and wellbeing. As some individual commissioners and providers, including schools, are not statutory members of Health and Wellbeing Boards, they should put in place arrangements to involve them in the development of the local plan, drawing on approaches already used in some areas such as Mental Health Advisory Panels or Children's Partnership Boards.

7.9 Key drivers for the quality of any local offer should be the local Health and Wellbeing Board's Joint Strategic Needs Assessment (JSNA) and Joint Health and Wellbeing Strategy. The JSNA should address children and young people's health and wellbeing, including mental health (31). Health and Wellbeing Boards, supported by the local government-led health and wellbeing system improvement programme and Public Health England, should ensure that both the JSNA and the Joint Health and Wellbeing Strategy address children and young people's mental health needs effectively and comprehensively. 
7.10 As well as drawing on the local plan, we consider that the local offer should be guided by a national ambition that clearly sets out the expectations and requirements for securing the best possible outcomes for children and young people's mental wellbeing. This will avoid the dangers of a postcode lottery while still ensuring a high degree of local flexibility. Over time, Government should consider whether elements of the national ambition should be placed on a more formal footing to ensure consistency of practice across the country.

\subsection{Developing an effective local system}

of care and support requires access to diverse and flexible services. In adult social care, there is a now a statutory duty on local authorities to shape the market to ensure adequacy of local provision. While the situation is not precisely analogous in children and young people's mental health our assessment is that those local areas exhibiting best practice have access to a range of providers, and, in particular, have harnessed the strength of the voluntary and community sector.

7.12 There is a particular need to coordinate the commissioning of community health and inpatient services (32). Within the current statutory system, the former is the responsibility of local commissioners and the latter the responsibility of the national commissioner, NHS England. If we are serious about moving away from a tiered model, then this commissioning needs to be joined up. This need for co-commissioning has been recognised by NHS England. At the same time, however, we want to avoid the mistakes of the past where we ended up with a patchwork quilt of intensive community crisis support and inpatient services.
7.13 The National Institute for Health and Care Excellence has a crucial role to play in framing a national ambition through the development of Quality Standards as well as guidance for health and social care, which are commissioned by the Secretaries of State for Health and Education (33). The quality standards will need to describe cost-effective evidence-based practice. They should provide clear descriptions of high priority areas for quality improvement. They will help organisations by supporting comparison of current performance, using measures of best practice to identify priorities for improvement. Though not mandatory, they are an important driver for change in the new arrangements for commissioning and service delivery in health and social care. It would be helpful if their recommendations could include further advice regarding implementation across the whole care pathway.

7.14 In supporting implementation and delivery of high quality care, we consider that CQC and Ofsted - with their distinct roles and responsibilities in health and education should develop a joint cross inspectorate view of how the health, education and social care systems are working together to improve children and young people's mental health outcomes and how this area should be monitored in future (34). 


\section{Access to information}

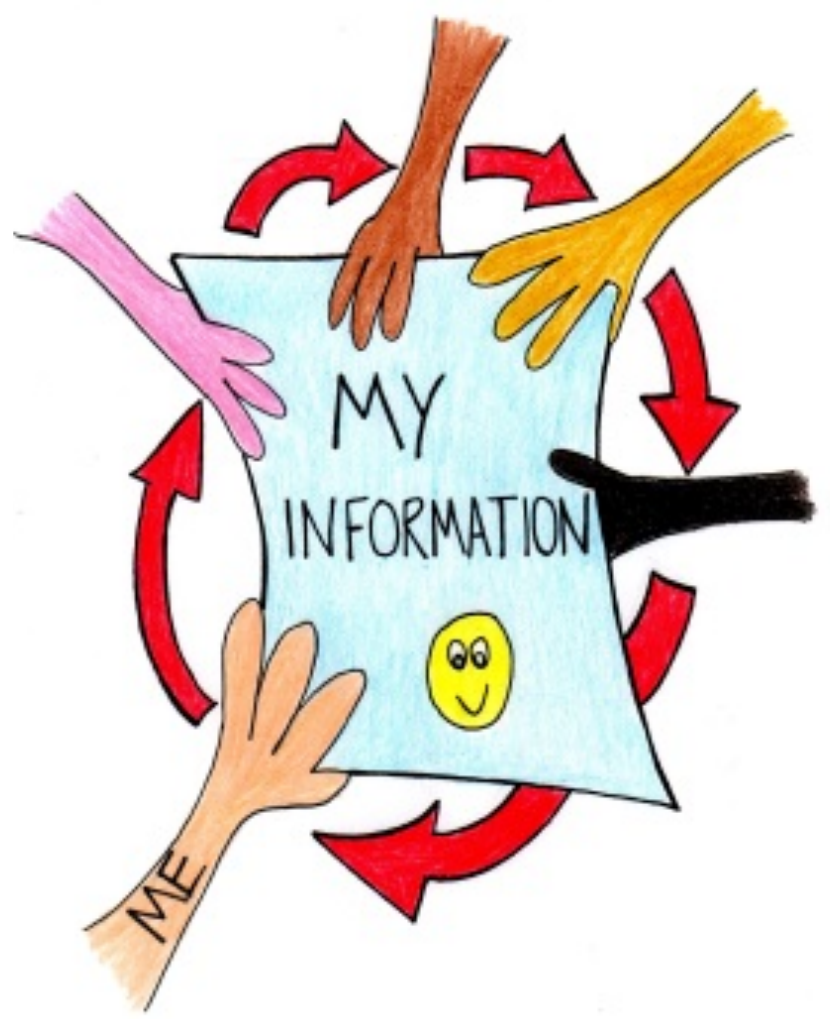

7.15 However, this is still not enough without access to information. Measurement is crucial to support continuous improvement. Support and services should be based on high quality, accurate data, but there are significant gaps in relation to children's mental health. The last children and young people's mental health prevalence survey was done over a decade ago, although the Department of Health has just started the process of commissioning the next one (35). We propose the commissioning of a regular prevalence survey of child and adolescent mental health every 5 years, giving particular consideration to including under-5s and ages over 15 (39). In addition, and in response to the growing international evidence base, the survey should be expanded to cover:

- New disorder codes (DSM 5, ICD-11) and conditions or issues that have grown in prominence since 2004, eg eating disorders, self-harm and the impact of social media and experience of cyberbullying; and

- The ability to analyse data by characteristics such as ethnicity and deprivation or whether a child is adopted or in care.

"If data collects meaningful information that can be useful for clinicians and patients alike to monitor their progress, data collection becomes part of the therapy."

A CAMHS psychologist who took part in the Taskforce engagement exercises.

7.16 At the same time, levels of investment in mental health services for children and young people should be transparent.

Accurate information on current levels of spend on children's mental health across agencies is a key gap. NHS England is working to improve the quality of data on adult mental health spend from April 2015 so that it will be able to identify the overall spend in primary and community care as well as mental health services and specialist commissioning. This has been built into the NHS planning process at CCG level. We propose that, in the future, this activity is extended to cover children's mental health spend by the NHS. It is also proposed that further work is undertaken to improve understanding of child and adolescent mental health funding flows across health, education, social care and youth justice to support a transparent, coherent, whole system approach to future funding decisions and investment (38).

7.17 The CAMHS Minimum Dataset, already in development, will allow specific outcome metrics by condition, activity and evidencebased interventions to support evaluation of 
the effectiveness of the care commissioned (35). To build on this work, it is important that routine data collection of key indicators of child and adolescent mental health service activity, patient experience and patient outcomes are properly co-ordinated and incentivised.

7.18 Data from the CAMHS Minimum Data Set will begin to flow no later than January 2016. It is likely that early data will be flawed and will take time for data completeness and quality to be such that conclusions can be drawn about access and waiting times. The Minimum Data Set does not cover investment levels. The implementation in 2015 and central flow of data through the Health and Social Care Information Centre ( $\mathrm{HSClC})$ must be a key priority for implementation at a national and local level. This includes ensuring that commissioners are placing into contracts the requirements for meaningful data collection, including outcomes monitoring.

7.19 NHS England has committed to developing access and waiting time standards in mental health. This applies to children and young people who will benefit in the first year with the introduction of the first ever waiting time standards in respect of early intervention in psychosis. In developing any access and waiting time standards, it should be a requirement that access to services is reported as time to different events in a pathway of care linked to delivery of NICE concordant treatment and measurement of outcomes (36 and 37).
7.20 In the meantime, many providers are already collecting data that can be used by commissioners, for instance:

- Members of the NHS Benchmarking Collaborative.

- Outcomes data collected by members of Children's Outcomes Research Consortium (CORC).

- $\quad$ The CYP IAPT datasets and outcome measures.

- Data collected for CAMHS Currencies.

- Health and Justice data.

7.21 Commissioning Support Units and Academic Health Science Networks should therefore be supporting commissioners to analyse local data collections, share best practice and pool knowledge and skills, mentoring new commissioners and delivering learning sets. This should include promoting the use of existing benchmarking tools by commissioners, for example, the Fingertips tool on the Mental Health Intelligence Network and the service snapshots and other information supplied by Public Health England. 


\section{To be accountable and transparent - chapter 7 summary}

Far too often, a lack of accountability and transparency defeats the best of intentions and hides the need for action in a fog of uncertainty. Our aim is to drive improvements in the delivery of care, and standards of performance to ensure we have a much better understanding of how to get the best outcomes for children, young people and families/ carers and value from our investment.

Much of what is needed can be done now by:

30. Having lead commissioning arrangements in every area for children and young people's mental health and wellbeing services with aligned or pooled budgets by developing a single integrated plan for child mental health services in each area, supported by a strong Joint Strategic Needs Assessment.

31. Health and Wellbeing Boards ensuring that both the Joint Strategic Needs Assessments and the Health and Wellbeing Strategies address the mental and physical health needs of children, young people and their families, effectively and comprehensively.

32. By co-commissioning community mental health and inpatient care between local areas and NHS England to ensure smooth care pathways to prevent inappropriate admission and facilitate safe and timely discharge.

33. Ensuring Quality Standards from the National Institute for Health and Care Excellence (NICE) inform and shape commissioning decisions

34. By Ofsted and CQC working together to consider how to monitor the implementation of the proposals from this report in the future.

35. The Department of Health fulfilling its commitment to complete a prevalence survey for children and young people's mental health and wellbeing, and working with partner organisations to implement the Child and Adolescent Mental Health Services dataset within the currently defined timeframe.

36. Developing and implementing a detailed and transparent set of measures covering access, waiting times and outcomes to allow benchmarking of local services at national level, in line with the vision set out in Achieving Better Access to Mental Health Services by 2020.

37. Monitoring access and wait measurement against pathway standards - linked to outcome measures and the delivery of NICE-concordant treatment at every step.

38. Making the investment of those who commission children and young people's mental health services fully transparent.

And subject to decisions taken by future governments:

39. Committing to a prevalence survey being repeated every five years. 


\section{Developing the workforce}

8.1 Professionals working with and supporting children and young people want to make a real and lasting difference to their lives.

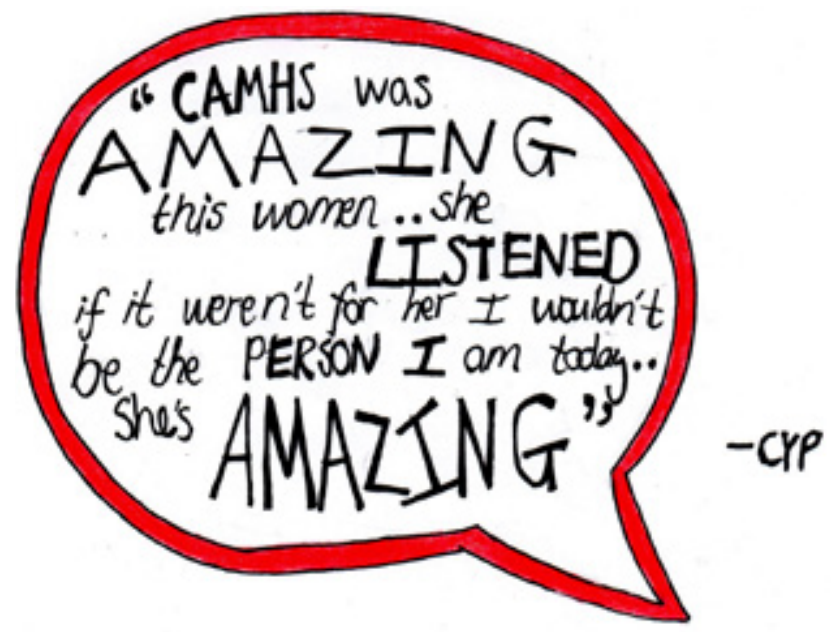

8.2 The national vision is for everyone who works with children, young people and their families to be:

- ambitious for every child and young person to achieve goals that are meaningful and achievable for them;

- excellent in their practice and able to deliver the best evidenced care;

- committed to partnership and integrated working with children, young people, families and their fellow professionals;

- $\quad$ respected and valued as professionals.

There is consistency in children and young people's views about the workforce qualities and behaviour they would like to see:

- A workforce which is equipped with the skills, training and experience to best support children and young people's emotional and mental wellbeing.

- Staff who are positive, have a young outlook, are relaxed, open-minded, unprejudiced, and trustworthy.

- Behaviour that is characterised by fairness, and a willingness to listen to, trust and believe in the child or young person.

- Everybody should work from a basis of asking and listening, being prepared to be helpful in creating understanding among other members of the workforce.

- Their processes should be transparent, honest, and open to being both inspected and clearly explained. Visible actions should result from such scrutiny, enabling children to voice their opinions.

- The workforce should provide real choice of interventions supported by enough resources to follow through, whilst remaining honest and realistic. 


\section{A workforce with the right mix of skills, competencies and experience}

8.3 Professionals across health, education and social care services need to feel confident to promote good mental health and wellbeing and identify problems early, and this needs to be reflected in initial training and continuing professional development across a range of professions (40). Professionals need to be trained to be able to:

- Recognise the value and impact of mental health in children and young people, its relevance to their particular professional responsibilities to the individual and how to provide an environment that supports and builds resilience.

- Promote good mental health to children and young people and educate them and their families about the possibilities for effective and appropriate intervention to improve wellbeing.

- Identify mental health problems early in children and young people.

- Offer appropriate support to children and young people with mental health problems and their families and carers, which could include liaison with a named appropriately trained individual responsible for mental health in educational settings.

- Refer appropriately to more targeted and specialist support.

- Use feedback gathered meaningfully on a regular basis to guide treatment interventions both in supervision and with the child, young person or parent/carer during sessions.

- Work in a digital environment with young people who are using online channels to access help and support.

\section{Universal settings}

8.4 Anybody who works with children and young people in universal settings such as early years provision, schools, colleges, voluntary bodies and youth services, should have training in children and young people's development and behaviours, as appropriate to their professional role.

8.5 This does not mean that professionals working in universal services should step in where a more specialised service is needed. But it does mean that, for example, a teacher who sees that a child is anxious, in a low mood, not eating or socialising as children and young people usually do, is withdrawn or behaving uncharacteristically, understands this child may need help. MindEd (www. minded.org.uk) is a useful resource for promoting this level of awareness in all staff who work with children and young people.

\section{Targeted and specialist services}

8.6 Staff who work in targeted and specialist services come from a range of professional backgrounds: social work, occupational therapy, nursing, clinical and educational psychology, psychotherapy, child and adolescent psychiatry and, with a growing number of 0-25 services, general adult psychiatry.

8.7 Staff in paediatric services make an important contribution to targeted and specialist mental health services for children and young people. Their role is likely to increase with a move towards greater integration between children's mental health provision and community paediatrics. The move towards 0-25 service models and integrated services means that, although discipline-specific training will remain the core of most professionals' training, interdisciplinary training and practice and cross-agency working will become increasingly important. 
8.8 Basic training in all disciplines should include an understanding of the interface between physical and mental health. These interactions indicate the need for: greater awareness of mental health problems amongst paediatric staff; greater awareness of physical health problems amongst mental health staff and the development of services models (such as paediatric liaison) which recognise the interaction and overlap between physical and mental health. A paediatric nurse working with young people with diabetes, for example, should be able to identify whether that young person also requires emotional or mental health support. All of these recommendations have significant implications for the training of staff in the children and young people's workforce. Enhanced, multi-professional training across the physical and mental health interface will be a key part of improving the experience of children and young people with physical and mental health problems.

\subsection{Effective access to support requires} improved communication between universal, targeted and specialist services, backed by a clear shared understanding of roles and responsibilities across all those involved in the system, so that children and young people do not fall between services, and receive timely and appropriate support. This implies the use of local reciprocal multi-agency and multi-professional training programmes for those involved in children and young people's services. A good example is the reciprocal training programme between practice nurses and local community mental health trust nurses in Health Education England North Central \& East London which is now available to be rolled out nationally.
8.10 The workforce in targeted and specialist services need a wide range of skills brought together in the CYP IAPT Core Curriculum. All staff should be trained to practise in a non-discriminatory way with respect to gender, ethnicity, religion and disability. This was considered in detail by the Vulnerable Groups and Inequalities Task and Finish Group. In addition, there are skills gaps in the current workforce around the full range of evidence-based therapies recommended by NICE. The CYP IAPT programme was commissioned with a modest budget to deliver training for a limited range of therapies to a prescribed group as a part of its transformation role. There are gaps in the training of staff working with children and young people with Learning Difficulties, Autistic Spectrum Disorder, and those in inpatient settings. Counsellors working in schools and the community have asked for further training to improve evidence-based care (43).

8.11 Skills and capabilities audits in the North West have shown not only deficits in terms of competencies but also gender and age issues that need to be addressed. $48 \%$ of staff in the survey were found to be due to retire in the next 10 years, and 90\% were female.

8.12 The Taskforce highlighted a number of initiatives in progress which could and should contribute to supporting professional capabilities. 


\section{Current action to develop workforce skills and competencies includes:}

For schools, the Carter Review of Initial Teacher Training ${ }^{68}$ (ITT) reported in January. It recommended commissioning a sector body to produce a framework of core content for ITT which would include child and adolescent development (41).

The revised Foundation Programme curriculum for doctors (covering the first two years of postgraduate training for doctors qualifying in the UK) will give increased prominence to mental health, and $45 \%$ of foundation trainees will rotate through a psychiatry post during their two years from 2016 to ensure that more doctors (many of whom will become GPs) have experience of working with patients with mental health issues. The opportunity should be taken to review whether a greater emphasis on children and young people's mental health could be incorporated.

The CYP IAPT programme currently works with partnerships covering 68\% of the 0-19 population. The Service Transformation programme includes training for existing service leaders, supervisors and therapists in the NHS, social care and voluntary sector in a range of evidence-based programmes, with a Mandate commitment for both Health Education England and NHS England to plan further roll-out (44).

The social work reform programme is placing a much stronger focus on the skills and competencies needed by child and family social workers. This includes identifying child development, physical and mental health and education needs and working in partnership with other professionals and organisations to provide the help a child or young person needs.

The Think Ahead initiative will provide a new cadre of top graduates training to specialise in adult mental health social work, including work with young adults.

The sector skills councils such as Skills for Care \& Development will also play an important role in shaping education and training for the workforce in support of the children and young people's mental health agenda.

\section{Developing a strategic approach to workforce planning}

\subsection{Adopting new commissioning}

arrangements with new models of contracting and performance monitoring would be a key driver to securing collaborative and coordinated working across local areas.

8.14 The established and proven CYP IAPT transformation initiative gives a platform on which to build and align the creation of a children and young people's mental wellbeing

68 Carter A (2015). Carter review of initial teacher training. London: Department for Education. workforce across agencies that is fit for purpose.

8.15 Planning for mental health services for children and young people in the future requires a bottom-up consideration of the current competencies and capabilities of the existing workforce as well as an understanding of the capacity that will be required to deliver a workforce fit for the future. The role of Health Education England and Local Education and Training Boards will be crucial to establish local requirements and local practice through locally led needs assessments of current workforce capability and capacity. 
"[We need] designated leaders to drive change across service and agency boundaries, and trained commissioners who know and understand how this would work and what they need to be commissioning. The Health Select Committee CAMHS report showed that many local authorities still do not consider children's emotional health and wellbeing and mental health as their core business. But of course it is! Their activity and priorities are the very foundation of building resilience and emotional intelligence in children."

Office of the Children's Commissioner as part of the Taskforce engagement exercises.

8.16 It is proposed that the Department of Health and Department for Education should work together with HEE, the Chief Social Worker for children and others, to design and commission a census and needs assessment of the current workforce working across the NHS, local authorities, voluntary sectors and independent sector as the first stage in determining a comprehensive cross-sector workforce and training strategy (45).

\section{Training for commissioners}

8.17 Traditionally, especially in the NHS, investment in training has focused on the provision of services. There is, however, no recognised standard training programme for commissioners of children's services or mental health services for children and young people. The recent mental health commissioning and leadership programme developed by NHS England and Academic Health Science Networks is organised around the principles of: data for commissioning, the use of the evidence base and leadership. All programmes include a module on child and adolescent mental health provision, and attendance at these accredited courses should be a requirement for all those working in commissioning of children and young people's services (42). 


\section{Developing the workforce - chapter 8 summary}

It is our aim that everyone who works with children, young people and their families is ambitious for every child and young person to achieve goals that are meaningful and achievable for them. They should be excellent in their practice and able to deliver the best evidenced care, be committed to partnership and integrated working with children, young people, families and their fellow professionals and be respected and valued as professionals themselves.

Much of what is needed can be done now by:

40. Targeting the training of health and social care professionals and their continuous professional development to create a workforce with the appropriate skills, knowledge and values to deliver the full range of evidence-based treatments

41. Implementing the recommendations of the Carter Review of Initial Teacher Training (ITT) to commission a sector body to produce a framework of core content for ITT which would include child and adolescent development.

42. By continuing investment in commissioning capability and development through the national mental health commissioning capability development programme.

With additional funding, a future government should consider:

43. Extending the CYP IAPT curricula and training programmes to train staff to meet the needs of children and young people who are currently not supported by the existing programmes.

44. Building on the success of the CYP IAPT transformation programme by rolling it out to the rest of the country and extending competencies based on the programme's principles to the mental wellbeing workforce, as well as providing training for staff in schools.

45. Developing a comprehensive workforce strategy, including an audit of skills, capabilities, age, gender and ethnic mix. 


\section{Making change happen}

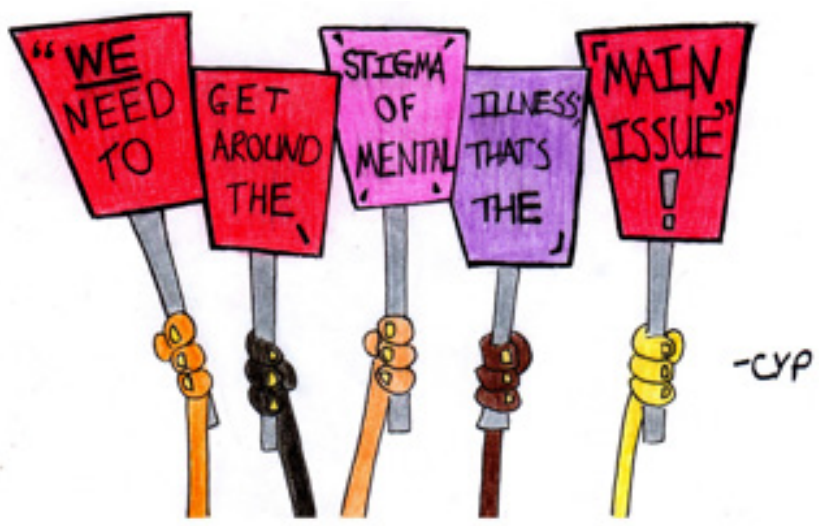

9.1 This report sets out a vision for a comprehensive approach to promoting, supporting and treating our children and young people's mental health, and to supporting their families. We have made a set of proposals to enable this vision to be translated into national and local frameworks. There is undoubtedly an urgency to act and in this section we set out how we might make a start.

\section{Building the evidence base}

\subsection{Throughout the report, we have} emphasised the paucity of good quality national information about meaningful outcomes as well as outputs in respect of child mental health services and how this can be corrected over the next few years, building on the early successes of the CYP IAPT programme.

9.3 If we are continuously to improve the mental health care and wellbeing of children and young people, we need data and evidence with which to do so (49). Good information is the foundation for commissioning; to understand need, to plan, secure and monitor services. In some areas, evidence is weak or entirely lacking as to the best interventions. Although lack of evidence should not be used as an excuse for lack of care, it is unethical and a waste of taxpayers' money to invest in interventions that have no evidence base - unless they are subject to rigorous evaluation.

9.4 This is one of the hardest challenges the system has: to secure acknowledgment of the limitations of our knowledge and not assume that interventions are without harm. There is good evidence that well-meaning interventions, with the best of intentions, can do more harm than good. A classic paper illustrating this is the McCord study of a multidisciplinary approach to child delinquency. In the 30 year follow up of the two groups, control versus active, every outcome was worse in the active group. ${ }^{69}$ Another was the mixed impact of suicide prevention in adolescents. $^{70}$ These examples illustrate the necessity to use an evidence base wherever possible and, if one is lacking, to ensure that research capacity is deployed to fill the gap.

69 McCord J (1978). A thirty year follow-up of treatment effects. American Psychologist 33: 284-289.

70 Ploeg J, Ciliska D, Dobbins M, Hayward S, Thomas H, Underwood J (1996). A systematic overview of adolescent suicide prevention programs. Canadian Journal of Public Health 87(5): 319-324. 
9.5 This re-emphasises the importance of NICE guidance and Quality Standards for those who plan, commission or provide services, and also the need for a world class research programme in child mental health and wellbeing supported by regular detailed prevalence surveys and reliable routinely collected comprehensive outcomes data.

\section{Making a start}

9.6 There are a number of proposals in this report directed at a national level that can only be properly considered during the next Parliament. However, we are keen that progress is made during 2015/16. Many of our proposals require a different way of doing business rather than further significant investment.

9.7 National organisations must play their part but we believe that even more progress can be made rapidly at the local level.

9.8 This will require local leadership and ownership. We therefore propose the development and agreement of

Transformation Plans for Children and Young People's Mental Health and

Wellbeing which will clearly articulate the local offer (46). These Plans would cover the whole spectrum of services for children and young people's mental health and wellbeing from health promotion and prevention work, to support and interventions for children and young people who have existing or emerging mental health problems, as well as transitions between services.

9.9 We would anticipate that the lead commissioner, in most cases the Clinical Commissioning Group, would draw up the Plans, working closely with Health and Wellbeing Board partners including local authorities. All these partners have an important role to play in ensuring that services are jointly commissioned in a way that promotes effective joint working and establishes clear pathways.

9.10 To support this, and in line with the announcement at the time of the Autumn Statement 2014, NHS England can make a specific contribution by prioritising further investment in those areas that can demonstrate robust action planning through the publication of local Transformation Plans that accord with the principles and ambitions set out in this report.

9.11 What is included in the Plan should be decided at a local level in collaboration with children, young people, families as well as provider and commissioner representatives and should address as many of the principles and proposals set out in the report as possible.

\subsection{At the same time, NHS England and} the Department of Health have recently invited proposals from CCGs to lead and accelerate co-commissioning arrangements for children and young people's mental health. The national response to this invitation was hugely encouraging and indicative of the potential to be harnessed by this report. Although only a limited number of areas could be chosen, as these projects develop, they will provide good examples of what can be achieved, alongside other relevant initiatives such as the Social Care Innovation Fund and the Department for Education's Voluntary and Community Sector Fund (48).

\subsection{Lead commissioners should ensure} that schools are given opportunities to contribute to the development of local Transformation Plans. The Department for Education is already leading work to improve the quality of teaching about mental health in Personal, Social, Health, and Economic (PSHE) lessons in schools, and is developing an evidence-based outcomes focused schools counselling strategy to encourage more and better use of counsellors in 
schools. This should equip schools to contribute to the development of the local Transformation Plans.

\section{Seeing it through}

9.14 The transformation of our national and local approach to children and young people's mental health and wellbeing will take time, at least the period of the next Parliament, aligning with the timescales of the Five Year Forward View. Change at the national level will need co-ordination across policy, investment, commissioning, regulation, training and inspection. Local areas will need ongoing support and guidance. It represents a complex and difficult journey and it will need strong political will combined with senior level leadership to see it through and be successful. Our closing proposal is therefore that there should be some clear governance at the national level to oversee the transformation of children's mental health with clear accountability for progress to the relevant Accounting Officers and Ministers (47).

\section{Making Change Happen - chapter 9 summary}

Much of what is needed can be done now by:

46. Establishing a local Transformation Plan in each area during 2015/16 to deliver a local offer in line with the national ambition. Conditions would be attached to completion of these Plans in the form of access to specific additional national investment, already committed at the time of the Autumn Statement 2014.

47. Establishing clear national governance to oversee the transformation of children's mental health and wellbeing provision country-wide over the next five years.

48. Enabling more areas to accelerate service transformation.

With additional funding, a future government should consider:

49. The development of an improved evidence base, on the safety and efficacy of different interventions and service approaches, supported by a world class research programme. 


\section{Conclusion}

10.1 The work of the Taskforce has revealed great potential to meet the desire for children and young people to have better support and care for their mental health. The economic argument and evidence for effective interventions make a strong case for putting national energy and effort into supporting the expectations that have emerged.

10.2 We have described a vision for our country in which child mental health and wellbeing is everybody's business, where our collective resilience and mental strength is regarded as an asset to the nation in the same way as we prize our levels of attainment, creativity and innovation.

10.3 We can start by doing what we know works, indeed already is working in some areas of the country, but is not being applied consistently.

10.4 The second step is to deliver the commitments already made and the initiatives already started that give us the fundamental building blocks that will help justify securing the third element.

10.5 With better data, transparency and accountability, the value of investment in mental wellbeing and care for child and young people can, and we believe will, be demonstrated and justified. A cycle of virtue can be created where, for each taxpayer's pound invested, the benefit for the individual and society can be realised with confidence.
10.6 In the meantime, there are targeted opportunities if resources can be identified through re-prioritisation and/or on an 'invest to save' basis. These have been set out clearly in the report and are illustrated by the additional money already identified for eating disorder services from April this year. And, of course, any local area can make a decision to re-prioritise its resources in favour of child mental health on the basis of existing national and local evidence of need and efficacy.

10.7 The work of the Taskforce has reconfirmed that we are by no means alone in the international community in grappling with how to give our children and young people a better start, to keep them safe and to help their mental health and resilience. It would be a hallmark of our progress if by 2020 we could truly say that England is leading the world in improving the outcomes for children and young people with mental health problems. We know that it is possible. But it will only happen if we decide with resolve and determination to place such a goal at the heart of the economic and social vision for our nation. 


\section{Glossary and Acronyms}

\begin{tabular}{|c|c|}
\hline$A \& E$ & Accident and Emergency \\
\hline ADHD & $\begin{array}{l}\text { Attention Deficit Hyperactivity Disorder } \\
\text { Neurodevelopmental disorder identified by behavioural symptoms that include } \\
\text { inattentiveness and impulsiveness. }\end{array}$ \\
\hline CAMHS & Child and Adolescent Mental Health Services \\
\hline CBT & Cognitive Behavioural Therapy \\
\hline CCGs & $\begin{array}{l}\text { Clinical Commissioning Groups } \\
\text { Statutory bodies clinically led that include all of the GP practices in their } \\
\text { geographical area. The aim of this is to give GPs and other clinicians the power } \\
\text { to take commissioning decisions for their patients. Each CCG has a constitution } \\
\text { and is run by its governing body, and is overseen by NHS England. }\end{array}$ \\
\hline CORC & CAMHS Outcomes Research Consortium \\
\hline CQC & $\begin{array}{l}\text { Care Quality Commission } \\
\text { Independent regulator of all health and social care services in England. }\end{array}$ \\
\hline CYP IAPT & $\begin{array}{l}\text { Children and Young People's Improving Access to Psychological Therapies } \\
\text { Programme }\end{array}$ \\
\hline DfE & Department for Education \\
\hline $\mathrm{DH}$ & Department of Health \\
\hline DSM-5 & $\begin{array}{l}\text { Diagnostic and Statistical Manual of Mental Disorders, Fifth Edition } \\
\text { Psychiatric classification and diagnostic tool, published in May 2013. The Fifth } \\
\text { Edition superseded the Fourth Edition which had been in use since } 2000 \text {. }\end{array}$ \\
\hline $\mathrm{HCP}$ & Healthy Child Programme \\
\hline HEE & Health Education England \\
\hline $\mathrm{HSCIC}$ & Health \& Social Care Information Centre \\
\hline H\&WBs & $\begin{array}{l}\text { Health and Wellbeing Boards } \\
\text { Statutory bodies based on upper-tier and unitary authorities in England drawing } \\
\text { together members of CCGs, local HealthWatch and the Local Authority. They } \\
\text { are charged with assessing the needs of their local population producing Joint } \\
\text { Strategic Needs Assessments and agreeing a Joint Health and Wellbeing } \\
\text { Strategy. The board also has responsibility for promoting integration of health } \\
\text { and care services. }\end{array}$ \\
\hline
\end{tabular}




\begin{tabular}{|c|c|}
\hline ICD-10 & $\begin{array}{l}\text { International Classification of Diseases, 10th Revision } \\
\text { The World Health Organization's medical classification list, in use since } 1994 . \\
\text { The 11th revision is due to be released in } 2017 .\end{array}$ \\
\hline ITT & Initial Teacher Training \\
\hline JSNAs & $\begin{array}{l}\text { Joint Strategic Needs Assessments } \\
\text { Process of reviewing and describing the current and future health and wellbeing } \\
\text { needs of a local population. }\end{array}$ \\
\hline LTC & $\begin{array}{l}\text { Long Term Condition } \\
\text { A health problem for which there is currently no cure, but the symptoms of } \\
\text { which may be managed with medication and other treatment. Examples include } \\
\text { asthma and diabetes. }\end{array}$ \\
\hline MUS & $\begin{array}{l}\text { Medically Unexplained Symptoms } \\
\text { Persistent physical complaints for which medical examination does not reveal an } \\
\text { obvious cause. }\end{array}$ \\
\hline NICE & National Institute for Health and Care Excellence \\
\hline Ofsted & Office for Standards in Education, Children's Services and Skills \\
\hline PHE & Public Health England \\
\hline PSHE & $\begin{array}{l}\text { Personal, Social and Health Education } \\
\text { Programme of learning that aims to equip young people with the knowledge, } \\
\text { understanding and skills they need to manage their lives healthily, safely, } \\
\text { productively and responsibly. }\end{array}$ \\
\hline SEND & Special Educational Needs and Disabilities \\
\hline YIACS & Youth Information, Advice and Counselling and Services \\
\hline
\end{tabular}




\section{Taskforce Membership}

\begin{tabular}{|c|c|}
\hline Name & Job Title \\
\hline Dr Martin McShane & $\begin{array}{l}\text { Co-Chair \& Director (Domain 2) Improving the quality of life for } \\
\text { people with Long Term Conditions, NHS England. }\end{array}$ \\
\hline Jon Rouse & $\begin{array}{l}\text { Co-Chair \& Director General for Social Care, Local Government \& } \\
\text { Care Partnerships, Department of Health. }\end{array}$ \\
\hline Dr Pru Allington-Smith & $\begin{array}{l}\text { Consultant Psychiatrist in Learning Disability Coventry \& } \\
\text { Warwickshire NHS Trust. }\end{array}$ \\
\hline Matthew Ashton & Assistant Director of Public Health (Knowsley) Liverpool. \\
\hline Dr Maggie Atkinson & Children's Commissioner for England. \\
\hline Mick Atkinson & Head of Commissioning, Place2Be. \\
\hline Prof Sue Bailey & Chair of Children \& Young Peoples Mental Health Coalition. \\
\hline Dr Laurence Baldwin & Royal College of Nursing. \\
\hline Johnny Benjamin & Expert by Experience. \\
\hline Sarah Brennan & Chief Executive, Young Minds. \\
\hline Sally Burlington & Head of Programmes Local Government Association. \\
\hline Prof Mick Cooper & $\begin{array}{l}\text { Prof of Counselling Psychology, CYP IAPT National Adviser for } \\
\text { Counselling, University of Roehampton. }\end{array}$ \\
\hline Dr Jacqueline Cornish & $\begin{array}{l}\text { National Clinical Director for Children, Young People \& Transition } \\
\text { to Adulthood, NHS England. }\end{array}$ \\
\hline Karen Cromarty & $\begin{array}{l}\text { Senior Lead Advisor for Children \& Young People, British } \\
\text { Association for Counselling \& Psychotherapy. }\end{array}$ \\
\hline Margaret Cudmore & Vice Chair of the Independent Mental Health Service Alliance. \\
\hline Rebecca Cotton & Director of Mental Health Policy, NHS Confederation. \\
\hline Dr Max Davie & Community Paediatrician. \\
\hline Dr Eustace DeSousa & $\begin{array}{l}\text { Deputy Director, National Team for Children, Young People \& } \\
\text { Families, NHS England. }\end{array}$ \\
\hline Keith Douglas & Managing Director, NHS South Commissioning Support Unit. \\
\hline Julia Faulconbridge & $\begin{array}{l}\text { Consultant Clinical Psychologist (Children, Young People \& } \\
\text { Families), British Psychological Society. }\end{array}$ \\
\hline Prof Peter Fonagy & $\begin{array}{l}\text { National Clinical Lead CYP \& IAPT, NHS England, \& Chief } \\
\text { Executive of the Anna Freud Centre. }\end{array}$ \\
\hline
\end{tabular}




\begin{tabular}{|c|c|}
\hline Name & Job Title \\
\hline Charlotte Gatherer & Expert by Experience. \\
\hline Vivienne Griffin & $\begin{array}{l}\text { Service Director, Disabilities and Mental Health, Wolverhampton } \\
\text { City Council. }\end{array}$ \\
\hline Peter Gibb & $\begin{array}{l}\text { Policy Lead, Prevention \& Access, Children \& Young People's } \\
\text { Mental Health \& Wellbeing Taskforce, Department of Health. }\end{array}$ \\
\hline Flora Goldhill & $\begin{array}{l}\text { Director, Children, Families \& Social Inclusion, Department of } \\
\text { Health. }\end{array}$ \\
\hline Ann Gross & $\begin{array}{l}\text { Director, Special Needs \& Children's Services Strategy, } \\
\text { Department for Education. }\end{array}$ \\
\hline Sharon Gray & Head Teacher, Netherfield Primary School. \\
\hline Dr Nick Hindley & $\begin{array}{l}\text { Consultant Child \& Adolescent Forensic Psychiatrist, Associate } \\
\text { Medical Director \& Oxford Health Lead, Named Doctor for } \\
\text { Children's Safeguarding, Thames Valley Forensic CAMHS, Oxon } \\
\text { FASS, \& Oxon \& Bucks CAHBS Teams. }\end{array}$ \\
\hline Dr Peter Hindley & $\begin{array}{l}\text { Consultant Child \& Adolescent Psychiatrist, Chair, Faculty of Child } \\
\text { \& Adolescent Psychiatry, Royal College of Psychiatrists. }\end{array}$ \\
\hline Netta Hollings & Health \& Social Care Information Centre. \\
\hline Mathew Hopkinson & $\begin{array}{l}\text { Assistant Director, 0-25 SEN \& Disability Unit, Department for } \\
\text { Education. }\end{array}$ \\
\hline Cathy James & MST Programme Lead, NHS England. \\
\hline Paul Jenkins & Chief Executive, Tavistock \& Portman NHS Foundation Trust. \\
\hline Dr Stephanie Lamb & $\begin{array}{l}\text { General Practitioner, Member of Adolescent Health Group, Royal } \\
\text { College of GPs. }\end{array}$ \\
\hline Dr Warren Larkin & $\begin{array}{l}\text { Consultant Clinical Psychologist, Lancashire Early Intervention in } \\
\text { Psychosis Service \& Clinical Director Children \& Families Network } \\
\text { Lancashire Care NHS. }\end{array}$ \\
\hline John Lees & $\begin{array}{l}\text { Associate Director of Commissioning, Birmingham South Central } \\
\text { Clinical Commissioning Group. }\end{array}$ \\
\hline Christine Lenehan & $\begin{array}{l}\text { Director of Council for Disabled Children \& Co-Chair of Child } \\
\text { Health Outcomes Forum. }\end{array}$ \\
\hline Terence Lewis & Ministerial Advisory Group for Mental Health Users \& Carers. \\
\hline Sarah-Jane Marsh & Chief Executive, Birmingham Children's Hospital. \\
\hline Nick McGruer & $\begin{array}{l}\text { Deputy Director Health, Disability \& Employment Directorate, } \\
\text { Department of Work \& Pensions. }\end{array}$ \\
\hline Paul Melody & Social Media Communication Expert. \\
\hline Dr Jane Mischenko & $\begin{array}{l}\text { Commissioning Lead, Children \& Maternity Services, } \\
\text { NHS Leeds Clinical Commissioning Groups. }\end{array}$ \\
\hline Karl Mittlestadt & Development Manager, Youth Justice Board for England \& Wales. \\
\hline
\end{tabular}




\begin{tabular}{|c|c|}
\hline Name & Job Title \\
\hline Dr Paul Mitchell & $\begin{array}{l}\text { Senior Clinical Nurse, Adult \& Youth Specialised Services, Greater } \\
\text { Manchester West NHS Trust. }\end{array}$ \\
\hline Zoe Mulliez & Public Policy Advisor, Healthwatch England. \\
\hline Dr Margaret Murphy & $\begin{array}{l}\text { Consultant Child and Adolescent Psychiatrist; Clinical Chair of the } \\
\text { Secure \& Specialised Mental Health Programme NHS England \& } \\
\text { Chair of Tier } 4 \text { CAMHS Clinical Reference Group. }\end{array}$ \\
\hline Kath Murphy & Head of Mental Health, Specialised Services, NHS England. \\
\hline Wendy Nicholson & Public Health Nursing, Department of Health. \\
\hline Anne O’Herlihy & Extended Scope Programme Manager CYP IAPT, NHS England. \\
\hline Alison O'Sullivan & $\begin{array}{l}\text { Vice President, Association of Directors of Children's Services \& } \\
\text { Director for Children \& Young People, Kirklees Council. }\end{array}$ \\
\hline Nick Page & Chief Executive, Solihull Metropolitan Borough Council. \\
\hline Claire Phillips & $\begin{array}{l}\text { Deputy Director, Children \& Young People's Mental \& Wellbeing } \\
\text { Taskforce, Department of Health. }\end{array}$ \\
\hline Kathryn Pugh & $\begin{array}{l}\text { Children \& Young People's Improving Access to Psychological } \\
\text { Therapies (CYP IAPT) Programme Lead. }\end{array}$ \\
\hline Dr Sandeep Ranote & $\begin{array}{l}\text { CAMHS Psychiatrist, Lead for Specialist Clinical Networks, NHS } \\
\text { England. }\end{array}$ \\
\hline Barbara Rayment & Director, Youth Access. \\
\hline Emma Rigby & Chief Executive, Association for Young People's Health. \\
\hline Wendy Russell & Head of Policy \& Operations, Health Education England. \\
\hline Eileen Scott & Expert by Experience. \\
\hline Anne Spence & $\begin{array}{l}\text { Policy Lead, Children \& Young People's Mental Health \& Wellbeing } \\
\text { Taskforce, Department of Health. }\end{array}$ \\
\hline Dawn Taylor & $\begin{array}{l}\text { Deputy Director, Children \& Young People's Mental Health, } \\
\text { Department for Education. }\end{array}$ \\
\hline Isabelle Trowler & $\begin{array}{l}\text { Chief Social Worker for Children \& Families, Department of } \\
\text { Education. }\end{array}$ \\
\hline Teresa Tunnadine CBE & Head Teacher, The Compton Secondary School. \\
\hline Karen Turner & Head of Delivery, Parity \& Esteem, NHS England. \\
\hline Kate Ward & $\begin{array}{l}\text { Policy Lead, Children \& Young Peoples Mental Health \& } \\
\text { Wellbeing, Department of Health. }\end{array}$ \\
\hline Dr Jon Wilson & Clinical Lead, Norfolk Youth Service. \\
\hline Miranda Wolpert & $\begin{array}{l}\text { Director of CAMHS Evidence based Practice Unit, National } \\
\text { Advisor on data for CYP IAPT programme. }\end{array}$ \\
\hline Dr Ann York & Professional Adviser on CAMHS, Care Quality Commission. \\
\hline
\end{tabular}




\section{Acknowledgements}

During its work, the Children and Young

People's Mental Health and Wellbeing

Taskforce has consulted and learned from

a wide range of people and organisations,

including health, education and care

professionals, academics, young people, parents and carers and policy experts. We have benefited greatly from their expertise and we would like to thank them all for their input and contributions to the report.

We would also like to thank Leanne Walker, GIFT Young Sessional worker, for providing illustrations. 


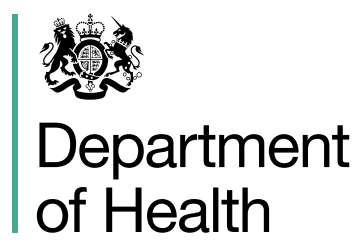

(C) Crown copyright 2015

2903393 Produced by Williams Lea for the Department of Health

\section{WHS England}

